\title{
Methodological Analysis of Damage Estimation in Hydraulic Infrastructures
}

\author{
Ramón Egea Pérez ${ }^{1}$ Francisco J. Navarro-González ${ }^{2, *}$, Mónica Cortés-Molina and Joaquín Melgarejo Moreno ${ }^{2}$ \\ 1 Department of Planification et travaux, Municipal water and sanitation company, 30008 Murcia, Spain; \\ regea@hotmail.es \\ 2 Department of Applied Mathematics, University of Alicante, 03690 Alicante, Spain; francisco.navarro@ua.es \\ 3 Department of Applied Mathematics, University of Alicante, 03690 Alicante, Spain; monica.cortes@ua.es \\ 4 Inst. del Agua y de las Ciencias Ambientales (IUACA), University of Alicante, 03690 Alicante, Spain; \\ jmelgar@ua.es \\ * Correspondence; regea@hotmail.es
}

\begin{abstract}
Critical infrastructures are those that are essential. For this type of infrastructure, it is necessary to implement analytical methodologies that will allow us to quickly obtain the susceptibility or resilience and possible damage generated in extreme precipitation episodes, through a holistic perspective in which the factors linked to hydrological risk intervene. In particular, urban hydraulic infrastructures are analyzed considering the degree of criticality, defined as the number of interactions on the different activities of the population. For this purpose, a hydrological risk analysis methodology is required. This methodology is focused on an integral approach of the system indicators to be analyzed and linked to the hydrological threat. This work proposes to delimit and analyze those factors that involve risk using an analytical expression. This model will estimate the damage to these infrastructures breaking down the factors involved in the risk equation and analyzing their variability according to the intrinsic characteristics linked to them as well as the interaction with external factors.
\end{abstract}

Keywords: flood damage methodology; hydraulic infrastructure; resilience; indicators

\section{Introduction}

Floods represent an increasingly frequent risk, because of the occurrence of extreme episodes of precipitation [1]. Regardless of other triggering factors of the catastrophic effects that these events represent, which increase the loss of human lives, [2], such as damage to essential infrastructures both from the physical and operational point of view, greatly affecting the normal activity of citizens, whose consequences are accentuated in urban environments of greater complexity where the holistic that develops between its various components greatly affected [3].

Despite technological development and the improvement of processes and the implementation of measures to increase resilience and improve infrastructure management, as well as the increase in preventive action, catastrophic hydrological events are frequent causing loss of human lives and significant damage to infrastructure and generating insecurity in the population and significant economic costs [4].

The analysis of hydrological risk from the territorial point of view is linked to the vulnerability of all or at least the most significant elements likely to be affected, regardless of the critical hazard parameters considered. In some cases, an assessment of damage per unit area $\left(€ / \mathrm{m}^{2}\right)$ is made according to the type of infrastructure potentially affected, incorporating the level of threat in the analysis area, obtaining a risk map identified by the level of damage obtained. As an example, and confirmed in various investigations, once the surface areas have been characterized and the different components located in them (crops, industries, urban areas, hospitals, schools, official bodies, and essential 
infrastructures in general) have been located, values are assigned per unit of surface area (risk and potential damage maps), thus obtaining the valuation of economic losses [5]. Thus, for example, in the case of infrastructures on land with an industrial classification, a value of $458 € / \mathrm{m}^{2}$ is assigned, while for urban land it would correspond to $434 € / \mathrm{m}^{2}$, assigning a value of $152 € / \mathrm{m}^{2}$ and $102 € / \mathrm{m}^{2}$ respectively to the content of the infrastructure.

In other cases, in addition to the characterization of the hydrological hazard, the vulnerability of the affected infrastructures is considered analytically, estimating the susceptibility and criticality of each one of them based on weighted indicators or assessments, given that in certain analysis methodologies the physical impact of the infrastructure is differentiated from the operational one [6-8]. Qualitative assessments are also proposed, given the complexity of obtaining real data and their heterogeneity.

In the face of climate change, with the greater frequency of extreme episodes of flooding, the adaptive capacity of urban infrastructure is becoming more evident, and that is why new designs and adapted elements to increase the response capacity of urban infrastructures are been incorporated. To this end, specific guides have been published, such as those of the Federal Emergency Management Agency [9, 10], and the Ministry for Ecological Transition of Spain [11].

In the case of essential infrastructures, and hydraulic infrastructures in particular, a complete characterization of these is carried out [12], and the corresponding definition of representative indicators, both physical and operational, improves the level of estimation of the vulnerability of the different components of these infrastructures [13]. In turn, a microzonal or local analysis of the hazard, with a comprehensive characterization of the critical factors that define it, in addition to a detailed analysis of its incidence, is essential to link and integrate these hazard factors in the hydrological risk.

In the research developed, a different analysis is proposed, where following various postulates, studies and experiences, an application methodology is proposed, of hydrological risk analysis in hydraulic infrastructures which can be equally applicable to other types of critical infrastructures, given its generalist nature, and in turn comprehensive, since all its indicators are linked and hierarchical [14]. It is through the mathematical development of indicators, characteristic functions and algorithms that the damage analysis methodology, which is proposed in this research, has been constituted. It is thus intended to contribute to improve the characterization of the susceptibility and resilience of urban hydraulic infrastructures, the obtaining of damage thresholds and their variability linked to the level of hydrological threat, and therefore decision-making.

The following is a summary of the main objectives of the research carried out:

1. Establishment of ranges and upper and lower threshold values of potential damage generated by hydrological hazard events.

2. Development and proposal of mathematical functions characteristic of the susceptibility and specific resilience of hydraulic infrastructure to hydrological hazards.

3. Definition of the critical factor most representative of the hydrological hazard and its link to the estimated potential damage.

4. Analysis and development of a mathematical algorithm for defining hydrological damage. Homogenization of damage values.

5. Analysis and proposal of mathematical relationships linking the risk index, potential damage and hydrological vulnerability.

6. Analytical development of the damage index and proposal of factors linked to the hydrological risk index.

There is currently an extensive specific bibliography on risk analysis with different approaches [15], probabilistic and deterministic [6]. Thus, different risk analysis methodologies, both descriptive and analytical are originated, which allow estimating not only the risk, but also the possible damages generated. 
As indicated by the research of [16], the damage generated by the lack of resilience of an infrastructure to a hazard can be translated into economic costs [17]. The degree of severity of the impact of the hazard and the vulnerability of a territory defines the potential damage, which is why this analysis makes it possible to create a territorial planning tool, while generating a flood risk map that allows for the analysis of alternatives and investment planning for decision-making [18].

ISDR-UN [19] represents an international strategy (UN) of global analysis of disasters that proposes damage mitigation strategies, promoting a "culture of prevention" for the mitigation of their effects. The methodology for flood risk prevention in the Valencian Community (Spain), PATRICOVA [20] incorporates the postulates of the European Directive on flood risk prevention EU (Directive 2007/60/C) [21], focusing on the assessment of potential damage to infrastructure through hydraulic variables (draught and speed). The research carried out by [2] and [22, 23] are limited to the analysis of seismic risk, although in the case of [2], the approach is more generalist. [3] studies risk management through indicators. [4] analyze the different aspects of vulnerability curves (depth-damage) and their application to urban environments. [24] analyzes the hazard in urban environments related to climate change. Flood risk and damage quantification is analyzed by [25] in the SUFRI project "Sustainable strategies of Urban Flood Risk Management to cope with the residual Risk", and in the iPRESARA project "Incorporation of anthropogenic risk components into integrated safety management systems for dams and reservoirs", as well as [26] analyses the impact of floods on urban centres, and [27] which analyses the tangible and intangible damage caused by episodes of flooding, among others.

On the other hand, the development of guidelines for recommendations, good practices and design of drainage elements provides resilience tools for adaptation to climate change [28-32].

\section{Materials and Methods}

\subsection{Basic concepts.}

The characterization of hydraulic infrastructure by means of indicators is particularly appropriate from the point of view of risk and adaptation to climate change, as proposed in this research, following some of the postulates of the research of [23] and [33, 34], the latter being "Development of Risk Management Indicators" a joint research of the InterAmerican Development Bank (IDB) and the University of Manizales, Colombia, which allows the following milestones to be obtained:

- $\quad$ Physical and operational definition of the hydraulic infrastructure and its potential susceptibility analysis, thus obtaining the response capacity (resilience) of the components of the hydraulic infrastructure in the face of hydrological hazards [35].

- Planning of actions and implementation of adaptation, prevention and mitigation (resilience) measures in the face of potential events of the hazards analyzed.

- The integration of processes (holistic approach), adapting the hydraulic infrastructure to the dynamics of hazards, reducing uncertainty and the degree of impact.

- Monitoring (temporal evolution) of the behavior of the hydraulic infrastructure, by basic component and the hydraulic infrastructure system as a whole.

Figure 1 shows the conceptual scheme of the methodology, where the risk (R) is calculated by the product of the hazard $(\mathrm{A})$ characterized by a magnitude and a frequency or return period, and the vulnerability $(\mathrm{V})$ in this case of the infrastructure. The hazard (A), in this case the hydrological one $A_{H}$ will be characterized by one or several critical factors and other complementary hazard factors of a more specific nature. Vulnerability 
$\left(V_{H}\right)$ is calculated through the analysis of susceptibility (S) and specific resilience. $(\alpha)$. Susceptibility is defined by physical and operational indicators, which make it possible to manage and assess the state of the various essential components of the water infrastructure system. The specific resilience indicators make it possible to quantify the effect of the hydrological hazard on the hydraulic infrastructure.

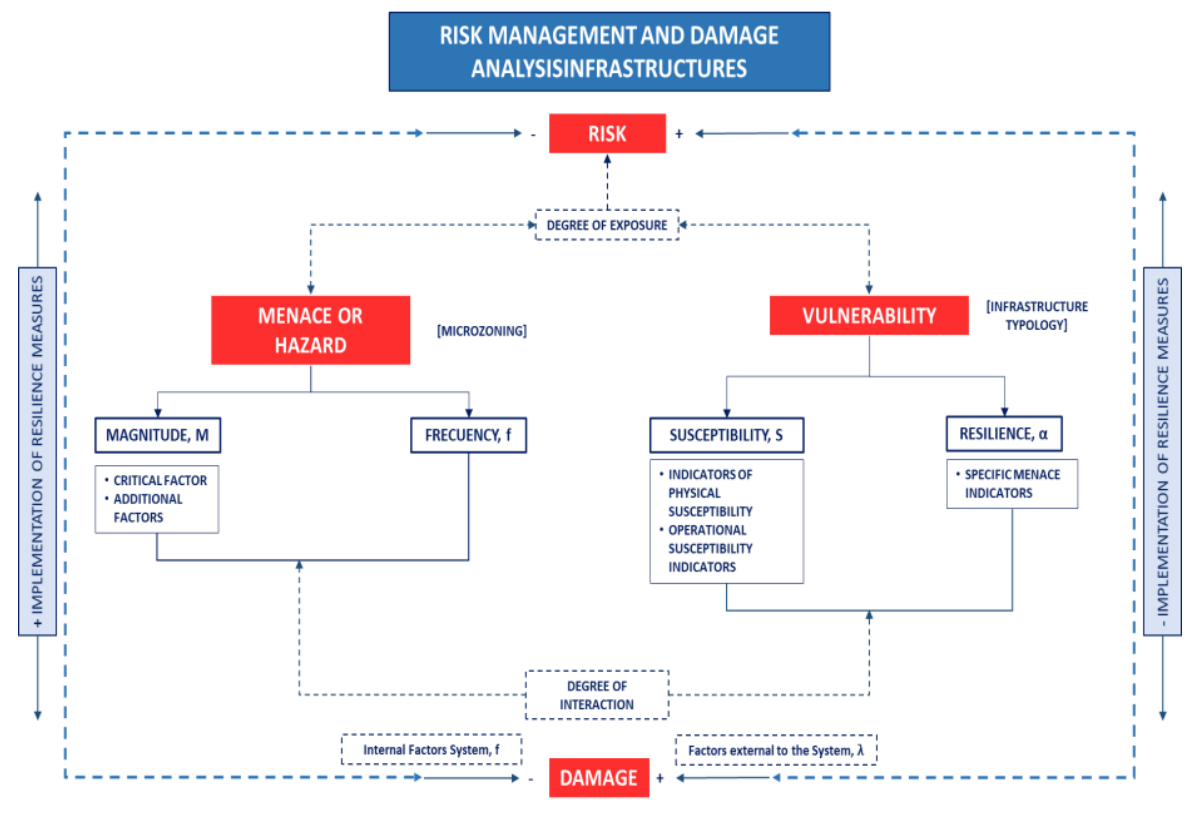

Figure 1. Conceptual scheme of the methodology. Source: Prepared by the authors.

In general terms, equation (1) presents the specific risk for hazard $\mathrm{k}$ and $\mathrm{i}$ types of infrastructure.

$$
R_{k i}=A_{k} \cdot V_{k i}
$$

In equation (2) the threat $A_{k}$ is obtained by multiplying the critical hazard parameter $P p_{k}$ and the $G(k)$ threat factors $F p_{k g}$, which can accentuate or attenuate the incidence of the critical parameter.

$$
A_{k}=P p_{k} \cdot \prod_{g=1}^{G(k)} F p_{k g}
$$

Equation (3) presents the hazard factors $F p_{k g}$.

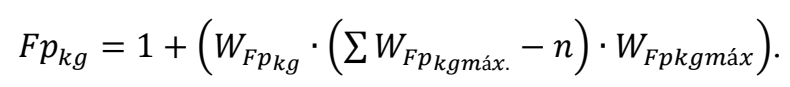

where the maximum weight of the specific threat factors are $W_{F p k g m a x}$. The threat is then represented by equation (4) and $P p_{k}$ the critical parameter defines the value of the initial threat that corresponds with the case when $F p_{k g}=1$.

$$
A_{k}=A_{0} \cdot \prod_{g=1}^{G(k)} F p_{k g} .
$$

Equation (5) shows the vulnerability $V_{k i}$ for each of the $k$ hazards and $i$ typologies of infrastructure is calculated by dividing the intrinsic susceptibility of the 
infrastructure $S_{i}$ of the infrastructure and the specific resilience of the component $i$ to hazard $k, \alpha_{k i}$.

$$
V_{k i}=\frac{s_{i}}{\alpha_{k i}}
$$

Equation (6) presents the expression of the intrinsic susceptibility of each type of hydraulic infrastructure, identifying two main components: the physical susceptibility $S_{\mathrm{p}_{\mathrm{i}}}$ determined by the $\mathrm{P}_{\mathrm{i}}$ physical susceptibility indicators and operational susceptibility $S_{\mathrm{O}_{\mathrm{i}}}$ determined by the $\mathrm{O}_{\mathrm{i}}$ operational susceptibility indicators.

$$
S_{i}=S_{\mathrm{p}_{\mathrm{i}}}+S_{O_{\mathrm{i}}}=\sum_{j=1}^{P_{i}} W_{S_{P_{\mathrm{ij}}}} \cdot I_{S_{P_{\mathrm{ij}}}}+\sum_{j=1}^{O_{i}} W_{S_{O_{\mathrm{ij}}}} \cdot I_{S_{O_{\mathrm{ij}}}} \cdot
$$

Equation (7) shows the details of the calculation of the resilience of each component $i$ to hazard $k$, which is defined by means of the resilience indices $\left(I \alpha_{k i l}\right)$.

$$
\alpha_{k i}=\sum_{l=1}^{L_{k i}} W \alpha_{k i l} \cdot I \alpha_{k i l} .
$$

Finally, equation (8) generically presents the specific risk of component $i$ in the face of hazard $\mathrm{k}$.

$$
R_{k i}=A_{k} \cdot \frac{s_{i}}{\alpha_{k i}}
$$

\subsection{Methodological development}

The proposed methodology is based on the specific hazards and the vulnerability of the hydraulic infrastructure components defined by the susceptibility and resilience indicators according to the postulates of [13], in addition to the considerations of [22, 23, 36]. Figure 2 shows a general outline of the proposed risk analysis methodological model, replicable to any system, with the exceptions indicated in the analyzed research. 


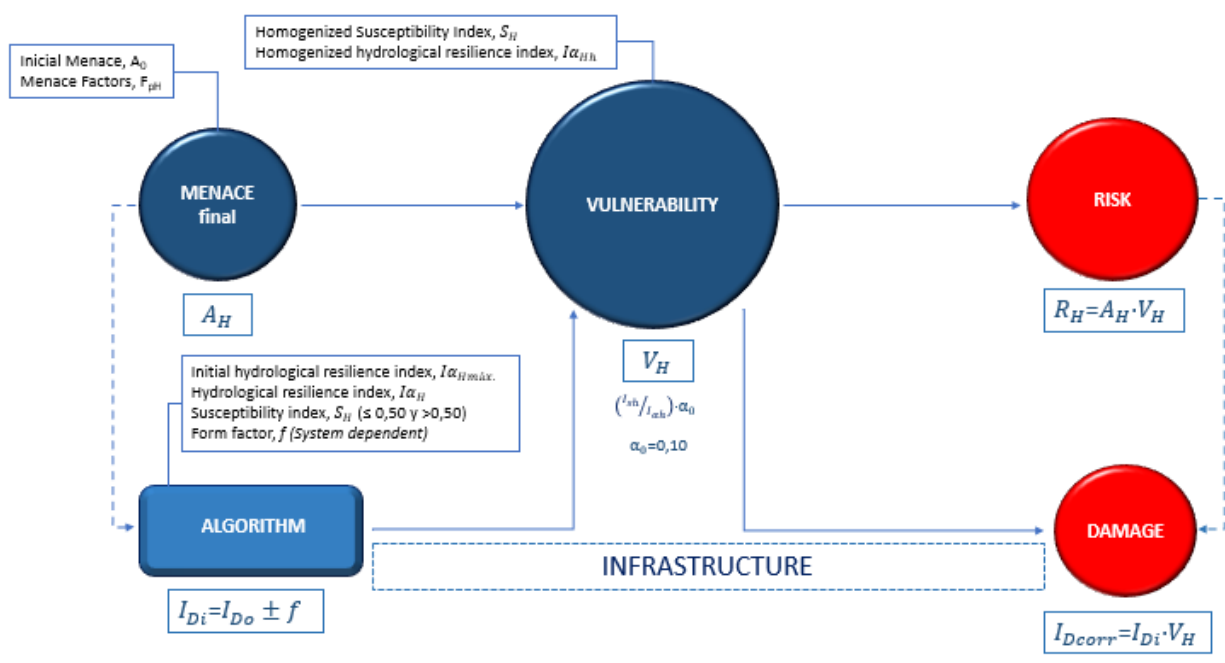

Figure 2. Proposed damage analysis methodological scheme. Source: Prepared by the authors.

The specific potential damage indices, $I_{D}$ are defined as:

$$
\begin{gathered}
I_{D p}=\frac{s_{p h}}{s_{t h}} \cdot \frac{I_{D i}}{I_{\alpha i}} \cdot R_{k i} . \\
I_{D o}=\frac{S_{o h}}{S_{t h}} \cdot \frac{I_{D i}}{I_{\alpha i}} \cdot R_{k i} .
\end{gathered}
$$

where $I_{D p}$ and $I_{D o}$ are the potential physical and operational damage indexes, $S_{p h}, S_{o h}$ and $S_{t h}$ the homogenized physical, homogenized operational and total susceptibilities, $I_{D i}$ and $I_{\alpha i}$ the initial potential damage and resilience indexes and finally $R_{k i}$ specific threat risk.

The corrected potential damage index, $I_{D c o r r}$. is obtained from the initial damage index calculated previously corrected by the factor $\left(\frac{I_{s h}}{I_{\alpha h}}\right) \cdot \alpha_{0}$ according to the following expression:

$$
I_{D c o r r .}=I_{D i .} \cdot\left(\frac{I_{s h}}{I_{\alpha h}}\right) \cdot \alpha_{0}
$$

where $I_{D i}, I_{S h}$ and $I_{\alpha h}$ are the initial potential damage, homogenized susceptibility and homogenized resilience indexes and $\alpha_{0}$ the residual resilience index $(0.10)$ that is the lower threshold value of resilience above which resilience is considered.

The damage represented by the corrected homogenized potential damage index $I_{D c o r r}$.can be expressed on the basis of the proposed investigation as:

$$
R_{k}=I_{\text {Dkcorr. }}+\lambda,
$$

where $I_{D c o r r}=I_{D i} \cdot V_{k}$ is the homogenized potential damage index corrected from the calculated initial damage index, $\lambda$ is a coefficient dependent on factors external to the infrastructure system and $I_{D i}$ the initial potential damage index, given by:

$$
I_{D i}=I_{D 0} \pm f .
$$

Being $f$ a factor in a way that depends on factors internal to the infrastructure system.

These concepts are related as Figure 3 shows: 


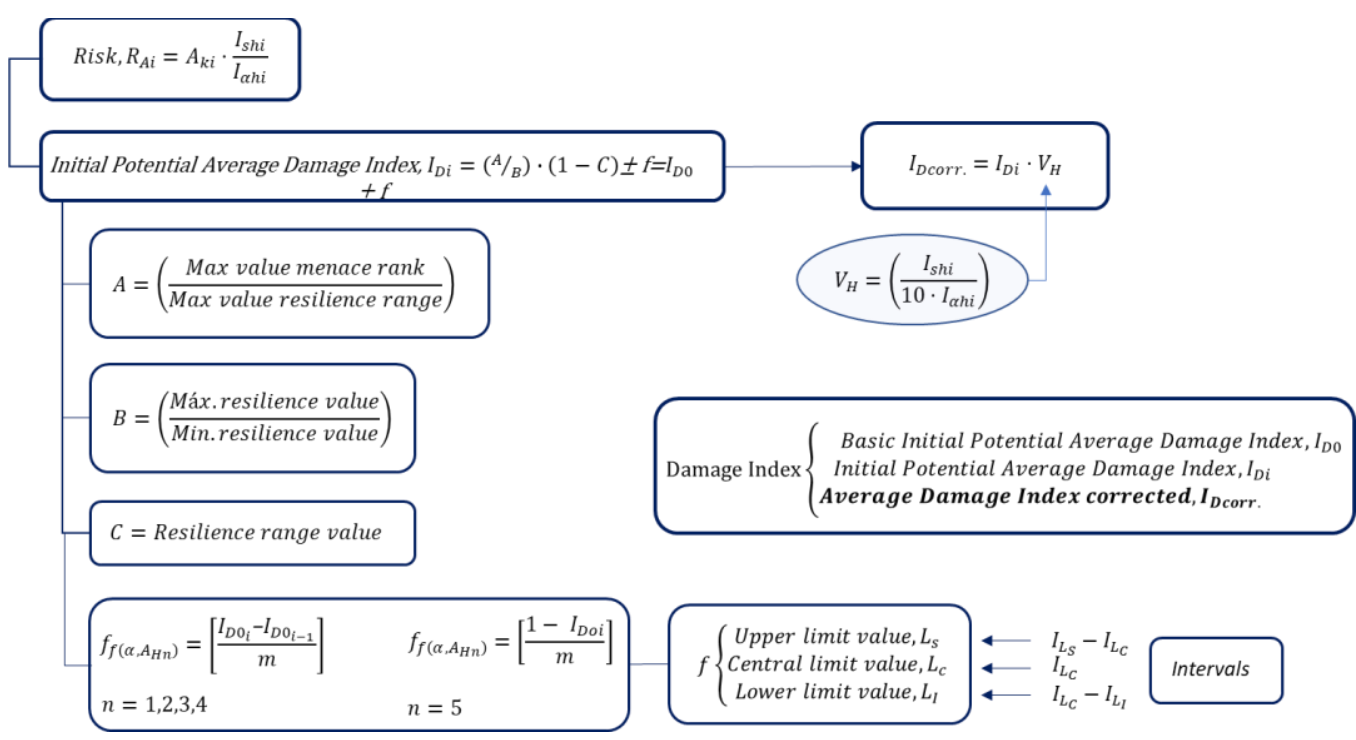

Figure 3. Flow chart for obtaining the hydrological hazard damage indices and the mathematical expressions used (algorithms). Source: Prepared by the authors..

The construction of the different indicators and indexes described, and which are used in the algorithms proposed are those analyzed and proposed in the research published by $[13,14]$ summarized in the different headings of the present methodological proposal.

The development and calculations of the indexes are represented in Figure 4:

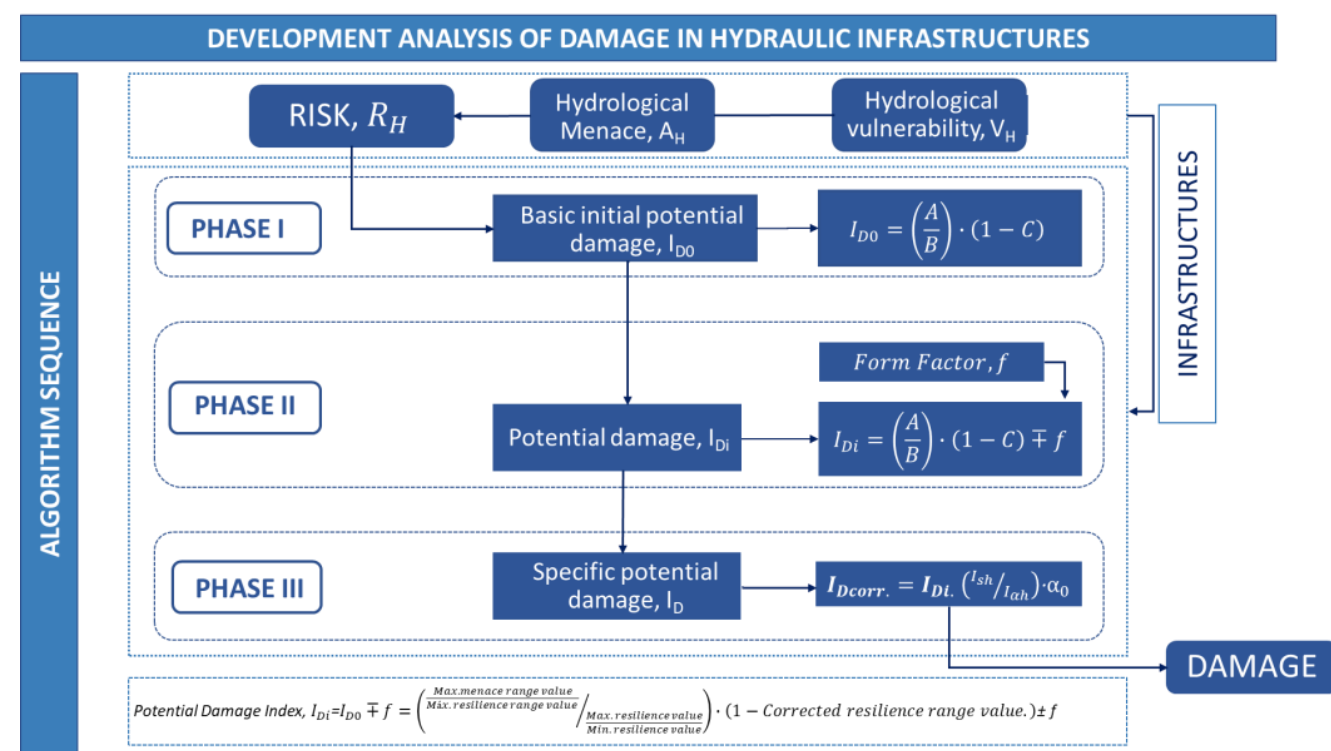

Figure 4. Analytical development and sequence to obtain the indexes. Source: Prepared by the authors.

Two levels of development of susceptibility and resilience in infrastructures are proposed, so by constructing indicators that make it possible to obtain parameterized and defining indexes of those (susceptibility and resilience) that integrate in this case, intrinsically, the degree of resilience and the level of the final hydrological threat 
(hydrological Microzonation), for each level of development of susceptibility indicated ( 0 $<$ Isi $\leq 0.50$, and $0.50<$ Isi $\leq 0.99$ ).

The establishment of these levels is due to the different degree of development of the infrastructure system depending on its location, among other aspects, and so that it is possible to apply the methodology described above, extending it to any infrastructure system and place.

From the analysis carried out, as well as from the consultation of other related research, a different increase in the variation of damage according to the hazard parameter or the level of vulnerability can be observed, with the damage value also following different distribution functions (log-normal, logarithmic, exponential, potential, linear, etc.).

According to the analysis carried out in this research, it is observed that the damage level decreases with the increase of resilience level and the decrease of susceptibility, $\mathrm{Si}$ comprised in the range $0.50<$ Isi $\leq 0.99$, according to Figure 5 .

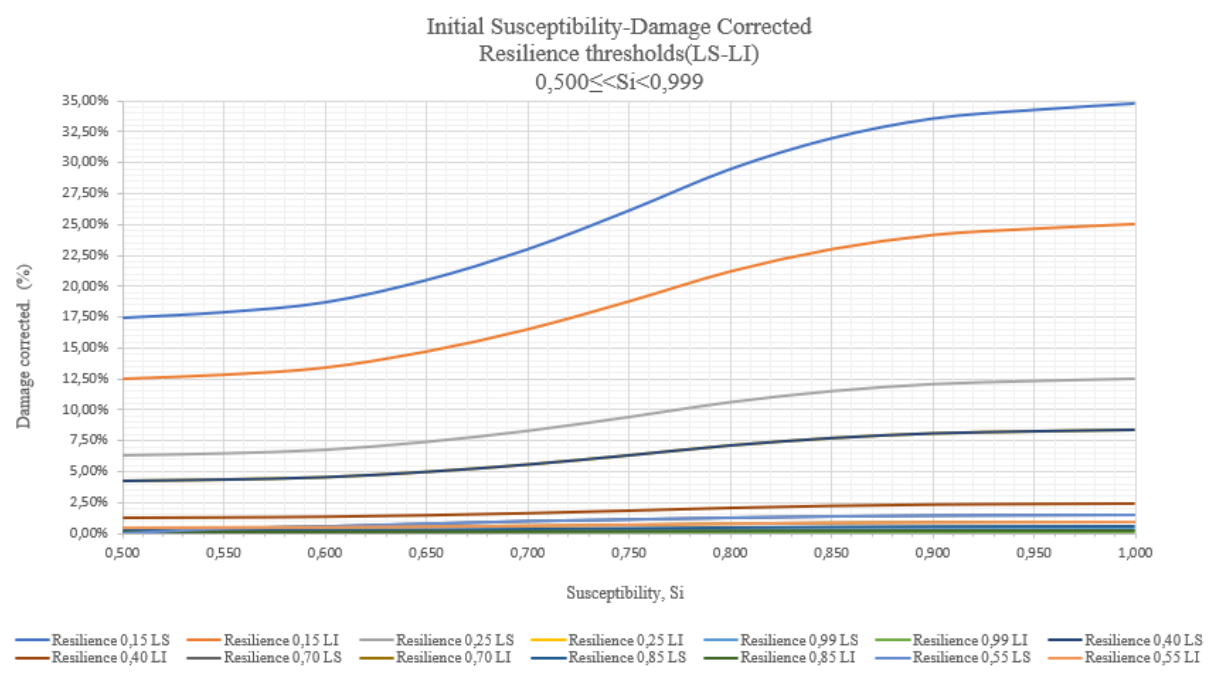

Figure 5. Graph of the evolution of damage according to intervals and upper limits, L.S. and lower limits, L.I. in relation to the susceptibility $0.500 \leqslant$ Isi $<0.999$, and the different levels of resilience, and for a given level of hydrological hazard, in this case level 4 of hydrological hazard $\left(0,30 \leqslant \mathrm{r}^{2} \mathrm{AH} \leqslant\right.$ 0.45). Source: Prepared by the authors.

The increase in damage in this case, being linear, i.e. following a distribution function of the $I_{D c o r r}=a-I_{s i}-b$ type, where,

$I_{\text {Dcorr }}$ : corrected damage index.

$I_{s i}$ : initial susceptibility index.

$a$ and $b$ : parameters of the linear function are developed as shown in the graphical functions in Figure 6, where, as an example of application, the variation of the damage value in relation to the susceptibility and resilience indices is observed. 


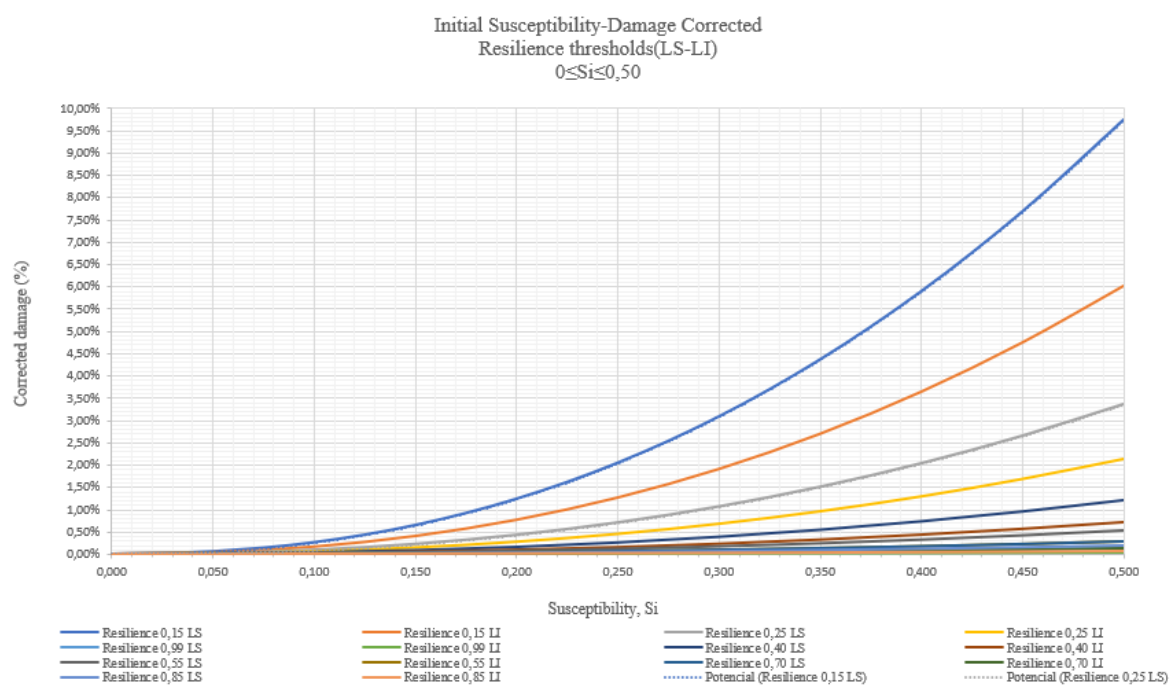

Figure 6. Graph of damage evolution according to intervals (L.S. and L.I.) in relation to the susceptibility $0 \leqslant \mathrm{Si} \leqslant 0.50$ and the different levels of resilience, and for a given level of hydraulic hazard, in this case level $4\left(0.30 \leqslant \mathrm{r}^{2} \mathrm{AH} \leqslant 0.45\right)$. Source: Prepared by the authors.

These susceptibility indexes are obtained through the definition, construction and valuation of specific indicators according to the proposed methodology corresponding to the research carried out by $[13,14]$ and shown in Figure 7 :

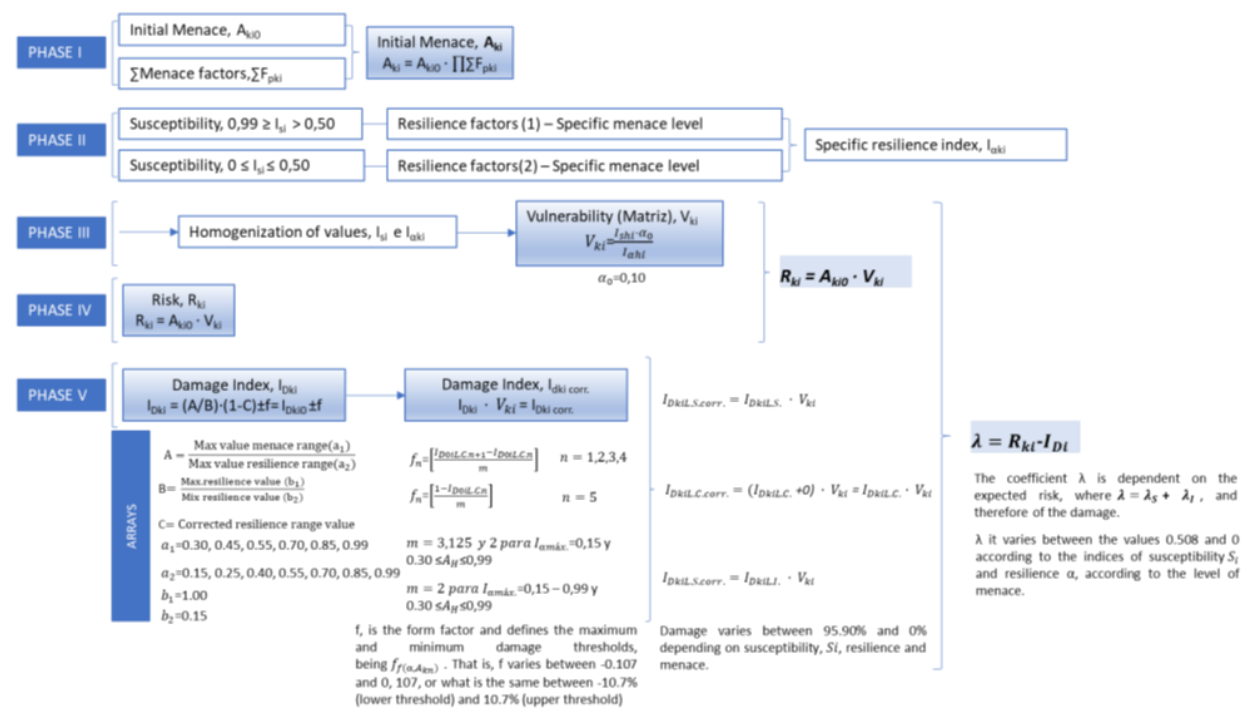

Figure 7. Proposed risk analysis methodological model. Source: Prepared by the authors.

After a trend analysis of the resilience values according to the level of threat, it is found that for a more precise definition of resilience, it is necessary to propose two levels of resilience, based on the susceptibility of an infrastructure system, so that there is a comparative homogeneity, as the degree of development of each hydraulic infrastructure system varies considerably depending on the degree of technological, economic and management progress that is carried out.

The analytical development of obtaining the resilience indicators according to the hydrological hazard interval and the degree of susceptibility $(0.50<$ Isi $\leq 0.99$ and $0.00<$ Isi $\leq .50$ ) is shown in Table 1 to Table 4. 
Table 1. Resilience corrected according to ranges for a susceptibility range $0.50<$ Isi $\leq 0.99$. Source: Own elaboration.

\begin{tabular}{|c|c|c|c|c|c|c|}
\hline \multirow{2}{*}{$\begin{array}{l}\text { Resilience Indi- } \\
\text { cator Ranges }\end{array}$} & \multirow[b]{2}{*}{ I $\alpha$ máx } & \multicolumn{5}{|c|}{ Hydrological Menace range $A_{H}$} \\
\hline & & $\begin{array}{c}\mathrm{r}_{1 \mathrm{AH}}<0.30 \\
0.30\end{array}$ & $\begin{array}{c}0.30<\mathrm{r} 2 \mathrm{AH} \leq 0.45 \\
0.45\end{array}$ & $\begin{array}{c}0.45<\text { r3AH } \leq 0.60 \\
0.60\end{array}$ & $\begin{array}{c}0.60<\mathrm{r}_{4 \mathrm{AH}} \leq 0.80 \\
0.80\end{array}$ & $\begin{array}{c}0.80<\mathrm{r}_{5 \mathrm{AH}} \leq 1 \\
1.00\end{array}$ \\
\hline $0 \leq \mathrm{r}_{1 \alpha} \leq 0.15$ & 0.15 & 0.150 & 0.129 & 0.116 & 0.099 & 0.082 \\
\hline $0.15<\mathrm{r}_{2 \alpha} \leq 0.25$ & 0.25 & 0.236 & 0.205 & 0.172 & 0.151 & 0.139 \\
\hline $0.25<\mathrm{r}_{3 \alpha} \leq 0.40$ & 0.40 & 0.444 & 0.347 & 0.291 & 0.256 & 0.235 \\
\hline $0.40<\mathrm{r}_{4 \alpha} \leq 0.55$ & 0.55 & 0.623 & 0.487 & 0.408 & 0.359 & 0.330 \\
\hline $0.55<\mathrm{r}_{4 \alpha} \leq 0.70$ & 0.70 & 0.783 & 0.611 & 0.512 & 0.451 & 0.414 \\
\hline $0.70<\mathrm{r}_{4 \alpha} \leq 0.85$ & 0.85 & 0.873 & 0.682 & 0.571 & 0.503 & 0.462 \\
\hline $0.85<\mathrm{r}_{5 \alpha}<1$ & 1.00 & 0.951 & 0.743 & 0.623 & 0.549 & 0.504 \\
\hline
\end{tabular}

Table 2. Hydrological hazard characteristic functions and coefficient of determination $\mathrm{R}^{2}$ for a susceptibility range $0.50<$ Isi $\leq 0.99$. Source: Own elaboration.

\begin{tabular}{ccc}
\hline Menace, $\mathbf{A H}_{\mathbf{H}}$ & & \\
\hline $\mathrm{r} 1 \mathrm{~A}<0.30$ & $\mathrm{I}_{\alpha \mathrm{H}}=-0.5609(\mathrm{I} \alpha \max ) 2+1.6147 \mathrm{I} \alpha \max -0.0946$ & $\mathrm{R}^{2}=0.9979$ \\
$0.30 \leq \mathrm{r} 2 \mathrm{~A} \leq 0.45$ & $\mathrm{I}_{\alpha \mathrm{H}}=-0.406(\mathrm{I} \alpha \max ) 2+1.2165 \mathrm{I} \alpha \max -0.06$ & $\mathrm{R}^{2}=0.997$ \\
$0.45<\mathrm{r} 3 \mathrm{~A} \leq 0.60$ & $\mathrm{I}_{\alpha \mathrm{H}}=-0.3189(\mathrm{I} \alpha \max ) 2+0.9898 \mathrm{I} \alpha \max -0.0411$ & $\mathrm{R}^{2}=0.9964$ \\
$0.60<\mathrm{r} 4 \mathrm{~A} \leq 0.80$ & $\mathrm{I}_{\alpha \mathrm{H}}=-0.2886(\mathrm{I} \alpha \max ) 2+0.8827 \mathrm{I} \alpha \max -0.0395$ & $\mathrm{R}^{2}=0.9964$ \\
$0.80<\mathrm{r} 5 \mathrm{~A}<1$ & $\mathrm{I}_{\alpha \mathrm{H}}=-0.2897(\mathrm{I} \alpha \max ) 2+0.8448 \mathrm{I} \alpha \max -0.047$ & $\mathrm{R}^{2}=0.9976$ \\
\hline
\end{tabular}

Table 3. Resilience corrected according to ranges, hazard level for a susceptibility range $0.00<$ Isi $\leq$ 0.50. Source: Prepared by the authors.

\begin{tabular}{ccccccc}
\hline \multirow{2}{*}{$\begin{array}{c}\text { Resilience Indi- } \\
\text { cator Ranges }\end{array}$} & I $\alpha$ max & \multicolumn{5}{c}{ Hydrological Menace range AH } \\
\cline { 3 - 7 } & & $\mathrm{r}_{1 \mathrm{AH}}<0.30$ & $0.30<\mathrm{r} 2 \mathrm{AH} \leq 0.45$ & $0.45<\mathrm{r}_{3 \mathrm{AH}} \leq 0.60$ & $0.60<\mathrm{r}_{4 \mathrm{AH}} \leq 0.80$ & $0.80<\mathrm{r} 5 \mathrm{AH} \leq 1$ \\
$0 \leq \mathrm{r}_{1} \leq 0.15$ & 0.15 & 0.300 & 0.45 & 0.60 & 0.80 & 1.00 \\
$0.15<\mathrm{r}_{2} \alpha 0.25$ & 0.25 & 0.420 & 0.219 & 0.162 & 0.119 & 0.082 \\
$0.25<\mathrm{r}_{3} \leq 0.40$ & 0.40 & 0.600 & 0.428 & 0.275 & 0.242 & 0.222 \\
$0.40<\mathrm{r}_{4 \alpha} \leq 0.55$ & 0.55 & 0.760 & 0.594 & 0.393 & 0.346 & 0.318 \\
$0.55<\mathrm{r}_{4} \leq 0.70$ & 0.70 & 0.900 & 0.703 & 0.497 & 0.438 & 0.402 \\
$0.70<\mathrm{r}_{4} \leq 0.85$ & 0.85 & 0.960 & 0.750 & 0.589 & 0.519 & 0.476 \\
$0.85<\mathrm{r}_{5}<1$ & 1.00 & 1.000 & 0.781 & 0.628 & 0.554 & 0.508 \\
\hline
\end{tabular}

Table 4. Hydrological hazard characteristic functions and coefficient of determination $\mathrm{R}^{2}$ for a susceptibility range $0.00<$ Isi $\leq 0.50$. Source: Prepared by the authors.

\begin{tabular}{ccc}
\hline Menace, $\mathbf{A H}_{\mathrm{H}}$ & & \\
\hline $\mathrm{r} 1 \mathrm{~A}<0.30$ & $\mathrm{I}_{\alpha \mathrm{H}}=-0.5609(\mathrm{I} \alpha \max ) 2+1.6147 \mathrm{I} \alpha \max -0.0946$ & $\mathrm{R}^{2}=0.9979$ \\
$0.30 \leq \mathrm{r} 2 \mathrm{~A} \leq 0.45$ & $\mathrm{I}_{\alpha \mathrm{H}}=-0.406(\mathrm{I} \alpha \max ) 2+1.2165 \mathrm{I} \alpha \max -0.06$ & $\mathrm{R}^{2}=0.997$ \\
$0.45<\mathrm{r} 3 \mathrm{~A} \leq 0.60$ & $\mathrm{I}_{\alpha \mathrm{H}}=-0.3189(\mathrm{I} \alpha \max ) 2+0.9898 \mathrm{I} \alpha \max -0.0411$ & $\mathrm{R}^{2}=0.9964$ \\
$0.60<\mathrm{r} 4 \mathrm{~A} \leq 0.80$ & $\mathrm{I}_{\alpha \mathrm{H}}=-0.2886(\mathrm{I} \alpha \max ) 2+0.8827 \mathrm{I} \alpha \max -0.0395$ & $\mathrm{R}^{2}=0.9964$ \\
$0.80<\mathrm{r} 5 \mathrm{~A}<1$ & $\mathrm{I}_{\alpha \mathrm{H}}=-0.2897(\mathrm{I} \alpha \max ) 2+0.8448 \mathrm{I} \alpha \max -0.047$ & $\mathrm{R}^{2}=0.9976$ \\
\hline
\end{tabular}

Figures 8 and 9 show the evolution of the mathematical functions that define resilience based on hazard and susceptibility levels. 


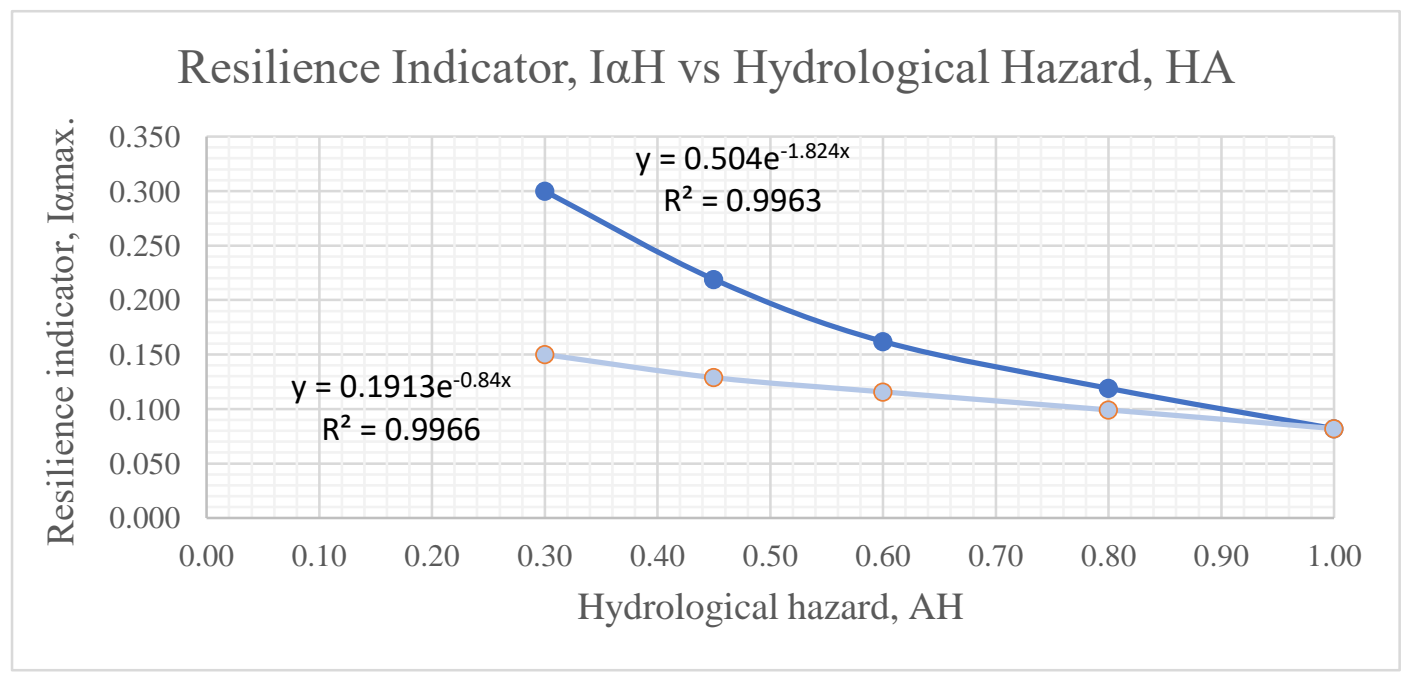

Figure 8. Variation of the resilience indicator in relation to the maximum values of hydrological hazard $\left(0 \leqslant \mathrm{r}^{1} \alpha \leqslant 0.15\right)$ when Isi $\leqslant 0.50$. (1) or Isi $>0.50$. (2). Source: Prepared by the authors.

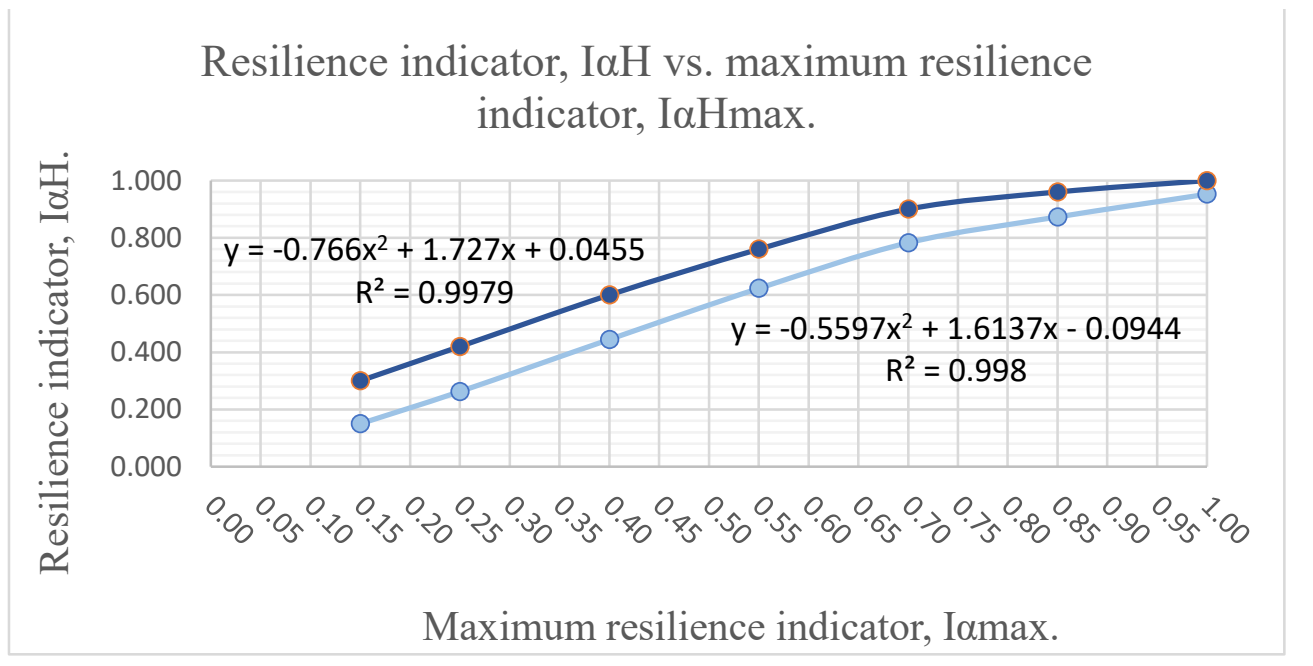

Figure 9. Variation of the resilience indicator values in relation to the maximum value of the hydrological hazard, case $\left(\mathrm{r}^{1} \mathrm{AH}<0.30\right)$ when Isi $\leqslant 0.50$. (1) or Isi $>0.50$. (2). Source: Prepared by the authors.

Finally, Figures 10 and 11 show the evolution of the various components of the hydrological risk equation and their correlation with the final corrected damage index. In these, we can observe the intervals of existence of the risk variables, according to the level of hazard, susceptibility, vulnerability, as well as the average level of damage in this case and the potential risk obtained. 
Evolution of Vulnerability, Risk and Damage vs Susceptibility and $\mathrm{A}_{\mathrm{H}}$

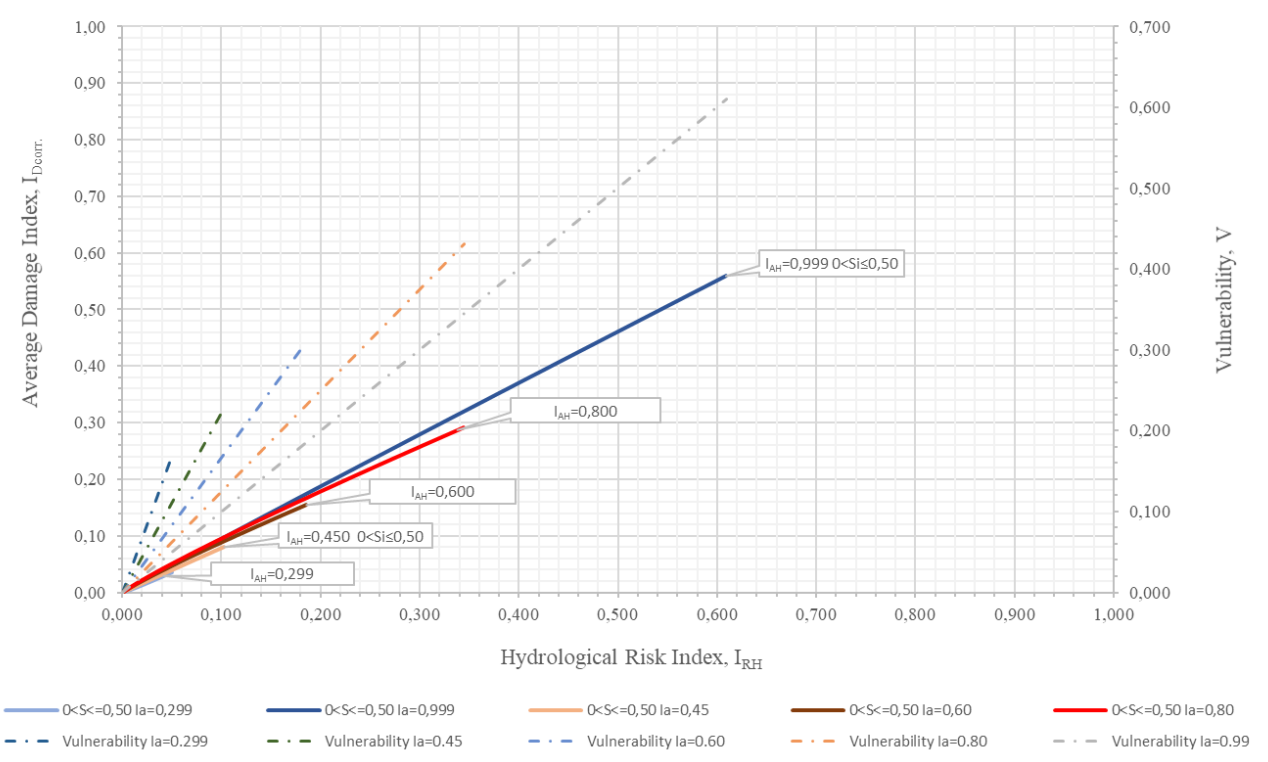

Figure 10. Evolution of the risk variables according to the level of susceptibility when $0 \leqslant \mathrm{Is} \leqslant 0.50$. Source: Prepared by the authors.

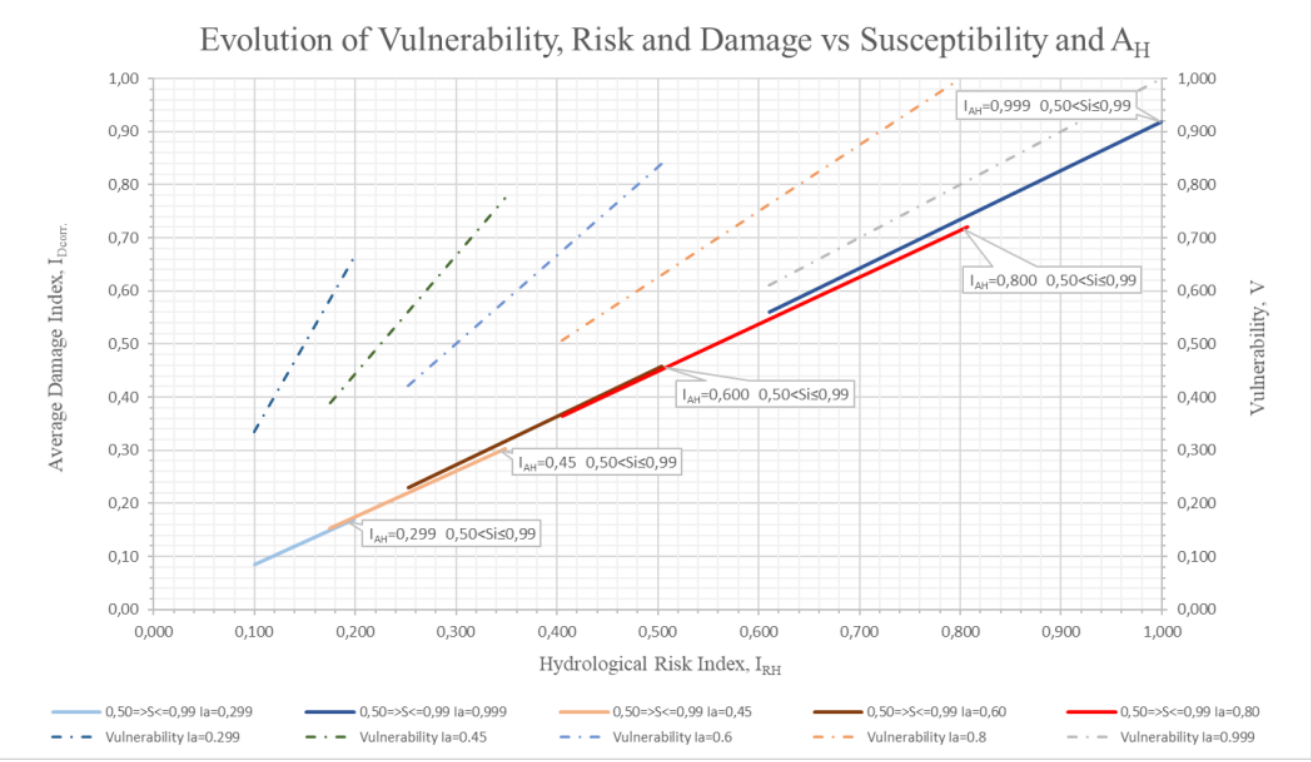

Figure 11. Evolution of the risk variables according to the level of susceptibility when $0.50<\mathrm{Is}_{\mathrm{s}} \leqslant 0.99$. Source: Prepared by the authors.

The application of the developed methodology would help in the planning of actions to increase resilience, damage mitigation in case of natural disasters of hydrological origin, as well as in the efficient management of the hydraulic infrastructure, increasing its sustainability, while allowing a monitoring of the corresponding indicators.

\section{Results}

In order to analyze the suitability of the methodology developed succinctly in the previous sections, its application is proposed in relation to the postulates included in the methodology developed in the Territorial Flood Risk Plan of the Valencian Community (Spain), PATRICOVA [20], which, although fundamentally referring to the hydrological risk of the territory, its postulates can be applied to the analysis of risk in infrastructures. 
This develops the analysis of damage by determining the height of the sheet of water that can be reached in the territory and the possible damage that can be caused to buildings, agricultural and livestock farms, industries and other installations and infrastructures located in the territory.

It should be noted that in relation to the morphology of the terrain with slopes greater than $5 \%$ with runoff or flood flow velocities greater than $3 \mathrm{~m} / \mathrm{s}$ and even with depths of less than $15 \mathrm{~cm}$, it can be considered dangerous and with a high probability of generating damage depending on the type of infrastructure as analyzed in Annex 1 of PATRICOVA [20], so it is essential to consider both variables (depth $Y$, and speed V) and thus obtain values closer to reality. However, it is also necessary in the case of analyzing the vulnerability of a particular infrastructure, to determine the susceptibility and resilience of this based on the definition of both physical and operational indicators, for which the methodology developed in the doctoral thesis [13] is proposed. It is from obtaining the indicators that the hydrological risk analysis is proposed, as well as the estimation of damage using algorithms and mathematical damage functions developed and based on various analyzed researches.

The methodology proposed in this research analyzes the use of both parameters, draft $\mathrm{Y}$ and velocity $\mathrm{V}$, in an integral way to obtain the hydrological threat or danger, and its link with the vulnerability of the infrastructures.

Table 5. Hydrological hazard levels (Pluvial Flooding) based on hydraulic variables, draught, and velocity $V \cdot Y, V^{2} \cdot Y$. Source: PATRICOVA [20] adapted.

\begin{tabular}{|c|c|c|c|c|c|c|c|}
\hline $\begin{array}{l}\text { Danger } \\
\text { Level }\end{array}$ & $\begin{array}{c}\text { Index } \\
\text { value }(0-1)\end{array}$ & $\begin{array}{c}\text { Variation } \\
\text { band }(0-100)\end{array}$ & Draft, Y (m) & $\begin{array}{c}\text { Velocity, V } \\
(\mathrm{m} / \mathrm{s})\end{array}$ & $\begin{array}{l}\text { Parameter tip- } \\
\text { ping stability, } \\
V \cdot Y \quad\left(\mathbf{m}^{2} / \mathbf{s}\right)\end{array}$ & $\begin{array}{c}\text { Parameter slip } \\
\text { stability, } V^{2} \\
Y\left(\mathbf{m}^{3} / \mathbf{s}^{2}\right)\end{array}$ & $\begin{array}{c}\text { Type of condi- } \\
\text { tion }\end{array}$ \\
\hline 1 & 1 & $100-80$ & $Y \geq 3.00$ & $V>2.50$ & $V \cdot Y \geq 7.00$ & $>1.23$ & \multirow{3}{*}{$\begin{array}{l}\text { Serious or very } \\
\text { serious area of } \\
\text { concern } \\
\text {-(people and infra- } \\
\text { structure) }\end{array}$} \\
\hline 2 & 0.85 & $79-60$ & $2.00 \leq Y<3.00$ & $2.00 \leq \mathrm{V} \leq 2.50$ & $V \cdot Y>3.00$ & $>1.23$ & \\
\hline 3 & 0.65 & $59-45$ & $1.00 \leq Y<2.00$ & $2.00>V \geq 1.50$ & $V \cdot Y \geq 1.50$ & $>1.23$ & \\
\hline 4 & 0.45 & $44-30$ & $0.50 \leq Y<1.00$ & $1.5>V \geq 1.00$ & $V \cdot Y \geq 0.50$ & $\geq 1.23$ & \multirow{3}{*}{$\begin{array}{c}\text { Zone of mild or } \\
\text { moderate affec- } \\
\text { tion } \\
\text { (people) }\end{array}$} \\
\hline 5 & 0.30 & $29-15$ & $0.15<Y<0.50$ & $1>V \geq 0.50$ & $V \cdot Y \geq 0.25$ & $<1.23$ & \\
\hline 6 & 0.15 & $14-0$ & $Y \leq 0.15$ & $\mathrm{~V}<0.50$ & $V \cdot Y \leq 0.08$ & $<1.23$ & \\
\hline
\end{tabular}

Upper and lower limit intervals or thresholds are established for the definition of susceptibility and resilience indices, as well as hydrological hazard levels defined on the basis of the parameters of flood flow depth and velocity.

It is from the integration of all the variables that make up the risk that the risk index and the damage index are obtained, establishing various upper and lower limit values for each susceptibility and resilience interval.

As an example of application and comparison with the "PATRICOVA" methodology [20], the case of a hydraulic infrastructure of a water supply system is proposed in which the level of affectation must be analyzed for a Y draught of $0.50 \mathrm{~m}$. From the curves proposed in this methodology, entering the graph with the estimated draught, $\mathrm{Y}=0.50 \mathrm{~m}$, the estimated damage is obtained. Entering the industry curve in Figure 12 with a draft $Y$ $=0.50 \mathrm{~m}, 14 \%$ of damage is obtained, being the damage in the generic case of $5 \%$. 


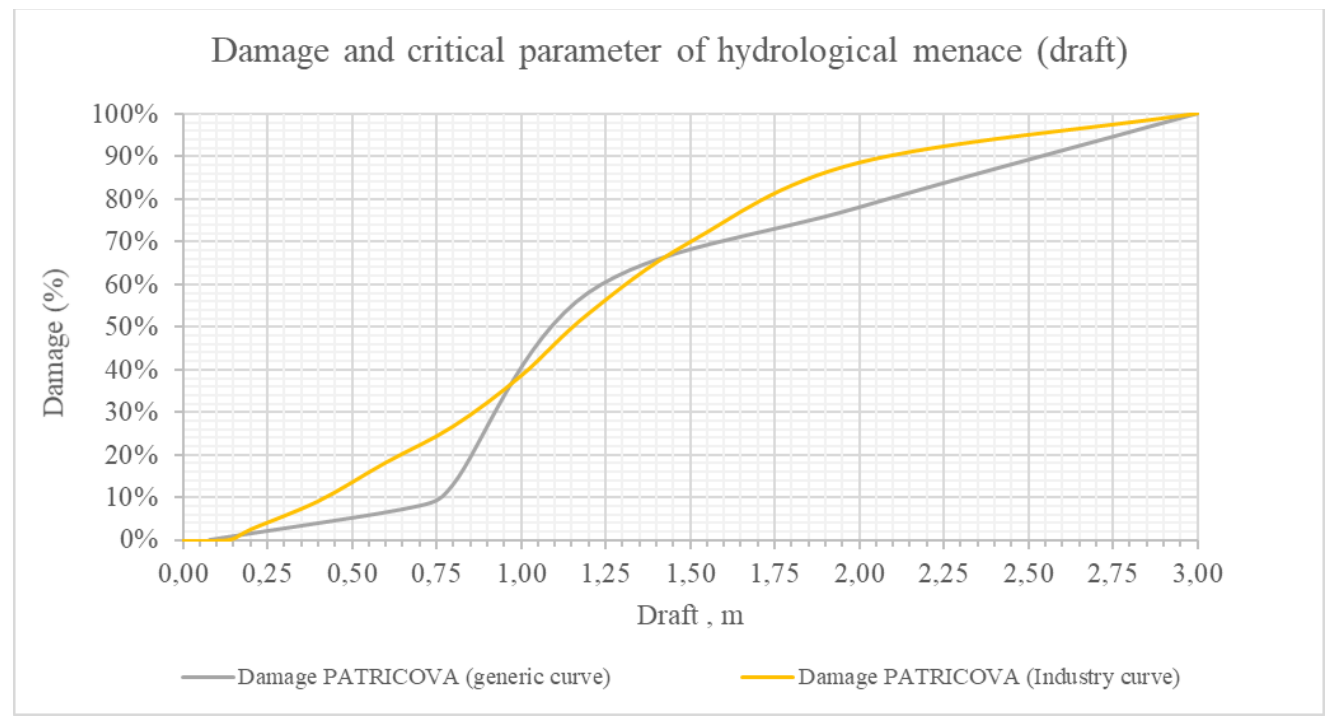

Figure 12. Damage-limestone analysis graph (generic curves and industries) according to PATRICOVA [20] . Source: own elaboration.

The values obtained, by means of the proposed methodology and using only the indicated draught $Y=0.50 \mathrm{~m}$ are shown in table 6.

In relation to the rest of the parameters, susceptibility and resilience, the following limiting values of susceptibility and an initial resilience of 0.15 have been considered, also obtaining the values of the estimated damage intervals.

Table 6. Intervals of limiting values of susceptibility $\mathrm{Si}$, resilience $\alpha$ and damage ID. Source: own elaboration.

\begin{tabular}{ccc}
\hline Susceptibility, Isi (0-1) & \multicolumn{2}{c}{ Damage IDcorr. (\%) } \\
\hline Upper Limit Value (UL) Interval $(0 \leq \mathrm{Isi} \leq 0.50)$ & Upper Limit (UL) & Lower Limit (LI) \\
\hline 0.99 & 28 & 19 \\
\hline Lower Limit Value (LI) Interval $(0.50<\mathrm{Isi} \leq 0.99)$ & Upper Limit (UL) & Lower Limit (LI) \\
\hline 0.50 & 7 & 4 \\
\hline Initial resilience, $\alpha(0-1)$ & 0.15 &
\end{tabular}

Considering now the product draught $\mathrm{Y}$ and velocity $\mathrm{V}$, of value 0.50 according to table 5, the following damage values are obtained, entering in Figure 13, shown below. The limit functions (upper and lower) of damage are represented according to the threshold values of susceptibility, in this case an initial resilience level has been set at $I_{\alpha}=$ 0.15 , thus setting a conservative criterion. 


\section{Damage corr. y Critical hydrological hazard parameter (draft)}

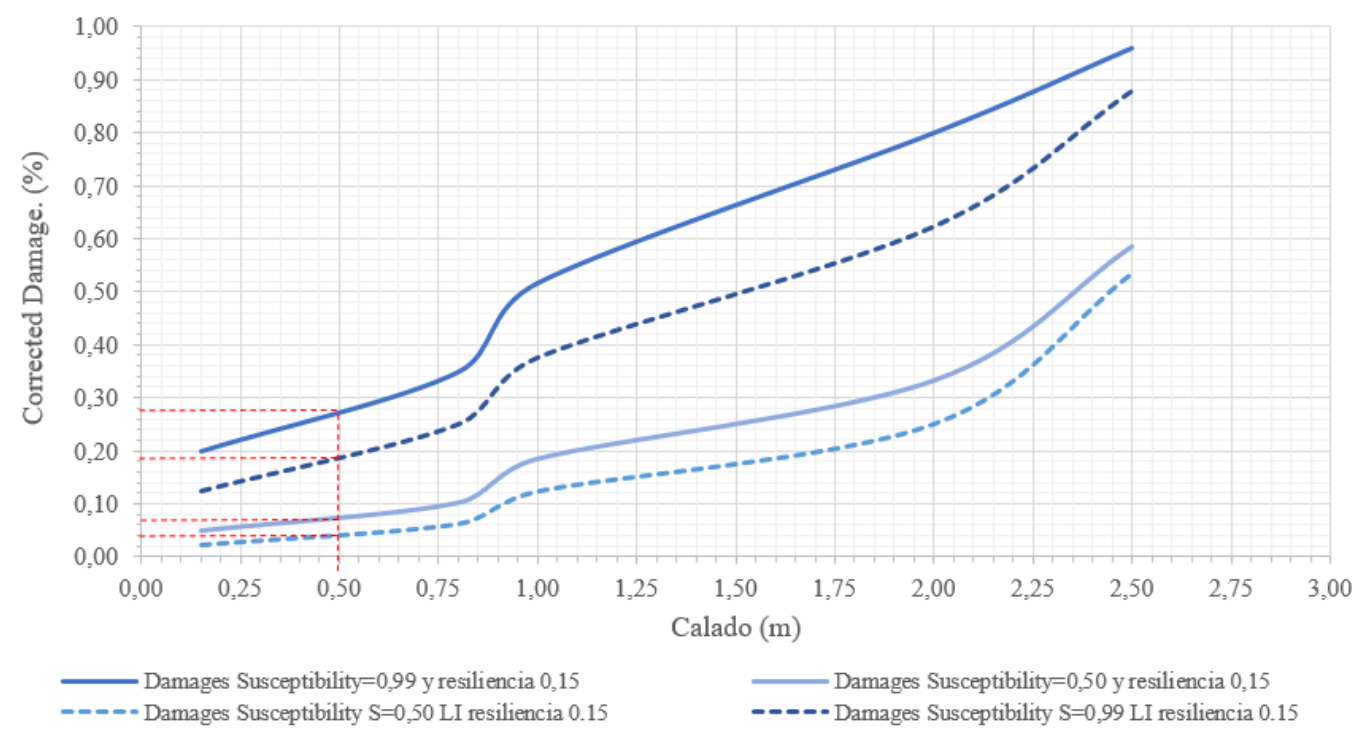

Figure 13. Graph of the analysis of the draft, $Y$, and damage, IDcorr. according to the proposed methodology. Damage limit values for Isi $=0.99$ and $0.50 ; \alpha=0.15$. Source: own elaboration.

As can be seen, when considering this product $V \cdot Y$, higher damage values are obtained than those obtained considering only the $\mathrm{Y}$ draught parameter.

Table 7. Intervals of limiting values of susceptibility Isi, resilience $\alpha$ and damage ID. Source: own elaboration.

\begin{tabular}{lcc}
\hline Susceptibility, Isi (0-1) & \multicolumn{2}{c}{ Damage IDcorr. (\%) } \\
\hline Upper Limit Value (UL) Interval $(0.50 \leq$ Isi $\leq 0.99)$ & Upper Limit (UL) & Lower Limit (LI) \\
\hline 0.99 & 35 & 25 \\
\hline Lower Limit Value (LI) Interval $(0<$ Is $\leq 0.50)$ & Upper Limit (UL) & Lower Limit (LI) \\
\hline 0.50 & 10 & 6 \\
\hline Initial resilience, $\alpha(0-1)$ & 0.15 & \\
\hline
\end{tabular}

In Figure 14, we obtain for the product of the draught by the velocity $0.50 \mathrm{~m}^{2} / \mathrm{s}$, a minimum resilience $\alpha=0.15$, and different susceptibility levels, $\mathrm{S}$, variable damage ranges $6 \%-10 \%$, and $25 \%-35 \%$ according to susceptibility limits (0.50 and 0.99 ). 


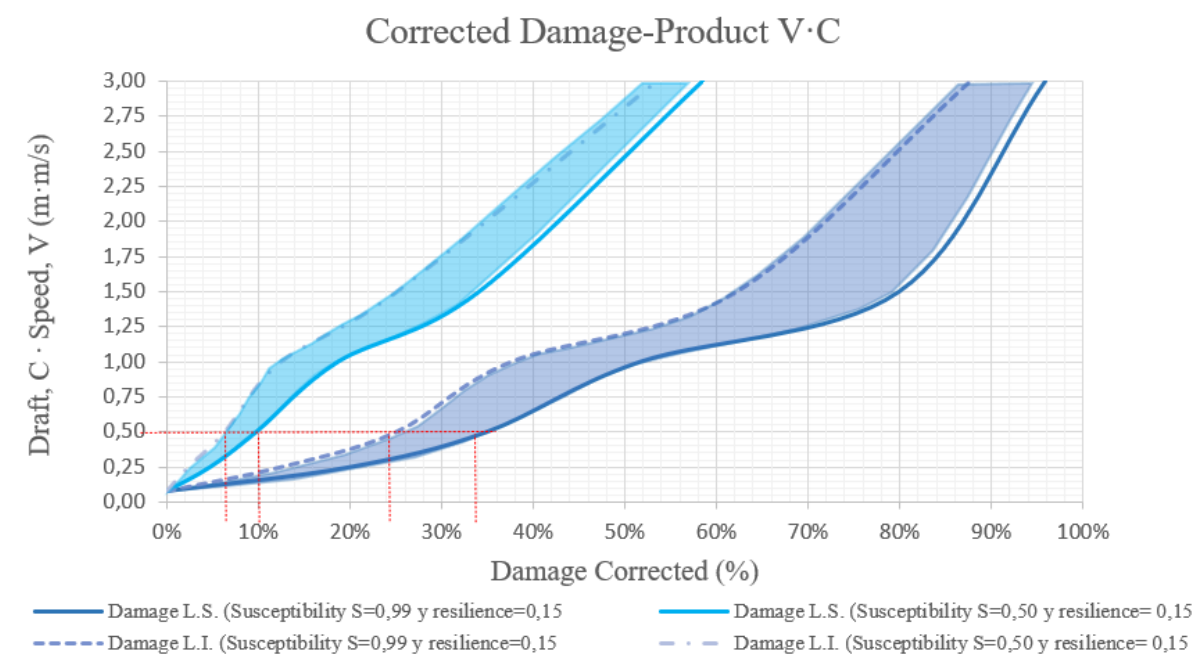

Figure 14. Graph of analysis of product $Y$ draught and V velocity, value 0,50 and damage values according to upper and lower limit intervals for $\mathrm{Si}=0,99$ and 0,$50 ; \alpha=0,15$. Source: own elaboration.

On the other hand, from the values of draught $Y=0.50 \mathrm{~m}$ and $Y-V=0.50 \mathrm{~m}^{2} / \mathrm{s}$ corresponding to level 4 of hydrological hazard according to table 5, and a proposed value of estimated damage ID $=14 \%$, the possible values of the hydrological hazard are obtained.

Table 8. Susceptibility limiting value ranges Isi, resilience $\alpha$ and damage ID.

\begin{tabular}{lcc}
\hline Susceptibility, Isi (0-1) & \multicolumn{2}{c}{ Hydrological Hazard (HAH) } \\
\hline Upper Limit Value (UL) Interval $(0.50 \leq \mathrm{I}$ si $\leq 0.99)$ & Upper Limit (UL) & Lower Limit (LI) \\
\hline 0.99 & 0.20 & 0.32 \\
\hline Lower Limit Value (LI) Interval (0<Isi $\leq 0.50)$ & Upper Limit (UL) & Lower Limit (LI) \\
\hline 0.50 & 0.52 & 0.63 \\
\hline Initial resilience, $\alpha(0-1)$ & 0.15 & \\
\hline
\end{tabular}

Compared to the PATRICOVA methodology [20], the values obtained vary considerably according to the susceptibility and resilience values estimated. The damage value of $14 \%$ would then correspond to a susceptibility value of $0.50<$ Isi $<0.99$. In this case, given that we would be at level 4 of hydrological hazard where it varies according to the interval (44-30), we select the hazard value 0.32 or 32 . By selecting this hazard value obtained, Figure 15, shows the damage values according to the established limits.

Table 9. Intervals of limiting values of susceptibility Isi, resilience $\alpha$ and damage ID. Source: own elaboration.

\begin{tabular}{ccc}
\hline Susceptibility, Isi (0-1) & \multicolumn{2}{c}{ Damage IDcorr. (\%) } \\
\hline Upper Limit Value (UL) Interval $(0.50 \leq$ Isi $\leq 0.99)$ & Upper Limit (UL) & Lower Limit (LI) \\
\hline 0.99 & 22 & 14 \\
\hline Lower Limit Value (LI) Interval (0<Isi $\leq 0.50)$ & Upper Limit (UL) & Lower Limit (LI) \\
\hline 0.50 & 5 & 2.5 \\
\hline Initial resilience, $\alpha(0-1)$ & 0.15 & \\
\hline
\end{tabular}




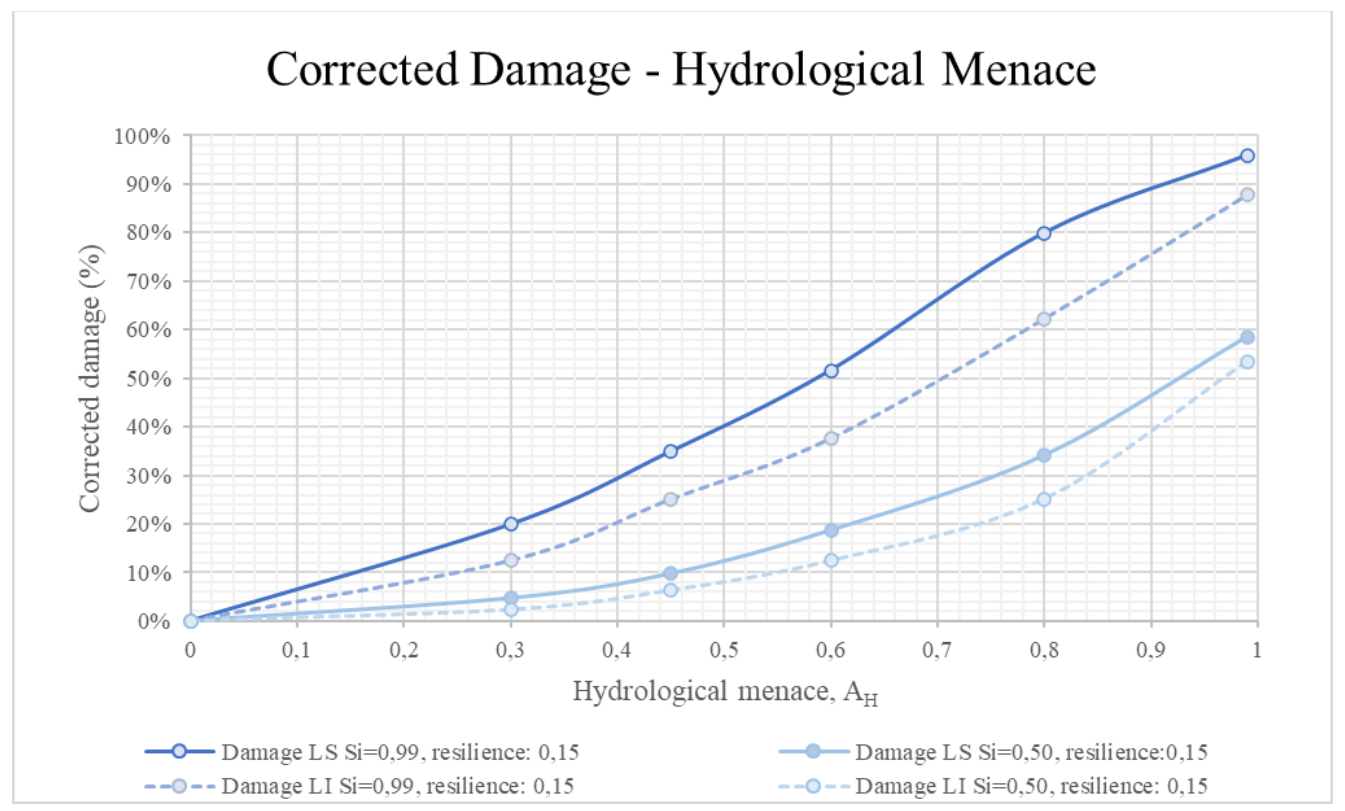

Figure 15. Graph of damage and hydrological hazard. Intervals, limits and values of susceptibility and resilience. Source: Prepared by the authors.

It is observed that for hazard level 4 (32), susceptibility values $0.50<$ Isi $\leq 0.99$ and resilience $0 \leq \alpha \leq 0.15$, the damage value obtained (lower limit, LI) coincides with that obtained in Figure 14, 14\%.

For the threat index obtained, a threat value of 0.45 is obtained according to the following table. This value of the hydrological threat could be affected by various local threat factors, although in this case they will not be considered.

Considering the different levels of resilience for a susceptibility of $0.50<$ Isi $\leq 0.99$, the estimated damages will be those indicated in the following table, according to the proposed methodology, showing that these damages would be in line with a susceptibility between Isi $=0.501$ and $\mathrm{Isi}=0.550$. Homogenizing values of susceptibility, $\mathrm{S}_{\mathrm{i}}$, and resilience, $\alpha$, and applying the formulation of risk, $\mathrm{R}$, it would be obtained that it varies between $R_{H}=0.17$ and $R_{H}=0.19$, respectively or initial $S=0.501$ and $S=0.550$.

$$
\begin{aligned}
& R_{H}=A_{H} \cdot V_{H}=A_{H} \cdot \frac{s^{h} / \alpha^{h}}{10}=0,1748 . \\
& R_{H}=A_{H} \cdot V_{H}=A_{H} \cdot \frac{S^{h / \alpha} h}{10}=0,191 .
\end{aligned}
$$

Table 10. Resilience values $\alpha$, and ranges of hydrological hazard and resilience, for a

\begin{tabular}{|c|c|c|c|c|c|c|}
\hline \multicolumn{7}{|c|}{ Corrected Hydrological Resilience Indicator ( $\left.\mathrm{I} \alpha_{\mathrm{Hc}}\right)$} \\
\hline \multirow{3}{*}{$\begin{array}{l}\text { Ranges Resilience } \\
\quad \text { indicators }\end{array}$} & \multirow{3}{*}{$\begin{array}{l}\text { Maximum resilience } \\
\text { indicator (I } \alpha \max .)\end{array}$} & \multicolumn{5}{|c|}{ Hydrological Menace Range } \\
\hline & & $\mathrm{r} 1_{A H}<0.30$ & $0.30 \leq \mathrm{r} 2_{\mathrm{AH}} \leq 0.45$ & $0.45<\mathrm{r} 33_{\mathrm{AH}} \leq 0.60$ & $0.60<\mathrm{r} 4_{\mathrm{AH}} \leq 0.80$ & $0.80<\mathrm{r} 5_{\mathrm{AH}} \leq 0.99$ \\
\hline & & $\mathrm{I}_{\mathrm{AH}} \mathrm{Hax}=0.299$ & $\mathrm{I}_{\mathrm{AH}} \mathrm{max}=0.45$ & $\mathrm{I}_{\text {AHmax }}=0.60$ & $\mathrm{I}_{\text {AHmax }}=0.80$ & $\mathrm{I}_{\mathrm{AH}} \mathrm{max}=0.999$ \\
\hline
\end{tabular}
susceptibility range $0.50<\mathrm{Isi} i \leq 0.99$. Source: Prepared by the authors. 


$\begin{array}{lllllll}0 \leq \mathrm{r} 1 \alpha \leq 0.15 & 0.15 & 0.150 & 0.129 & 0.116 & 0.099 & 0.082\end{array}$

Table 11. Damage for a level 4 hydrological hazard, Susceptibility Isi (0.500-0.550) and resilience $\alpha \leq 0.15$. Source: Prepared by the authors.

\begin{tabular}{cccc}
\hline \multirow{3}{*}{ Hydrological resilience } & \multirow{2}{*}{ Limits } & \multicolumn{2}{c}{ Hydrological Menace Level 4 (44-30) } \\
\cline { 3 - 4 } & & $0.30 \leq \mathrm{r}^{2} \mathrm{AH} \leq 0.45$ & $0.30 \leq \mathrm{r}^{2} \mathrm{AH} \leq 0.45$ \\
\cline { 3 - 4 } & & $\mathrm{Isi}=0.501$ & $\mathrm{Isi}=0.550$ \\
\hline \multirow{3}{*}{$0 \leq \mathrm{r}^{1} \alpha \leq 0.15$} & Upper value range & $17,46 \%$ & $19,17 \%$ \\
\cline { 2 - 4 } & Mean value range & $14,99 \%$ & $16,46 \%$ \\
\cline { 2 - 4 } & Lower value range & $12,52 \%$ & $13,75 \%$ \\
\hline
\end{tabular}

\section{Discussion}

Next, based on the analysis carried out, the variation (upper and lower limits) of the risk and potential damage according to the level of threat, and the ranges of the susceptibility index considered $(0 \leq$ Isimax. $\leq 0.50$ and $0.50<$ Isimax. $\leq 0.99)$ is observed. Figure 14.

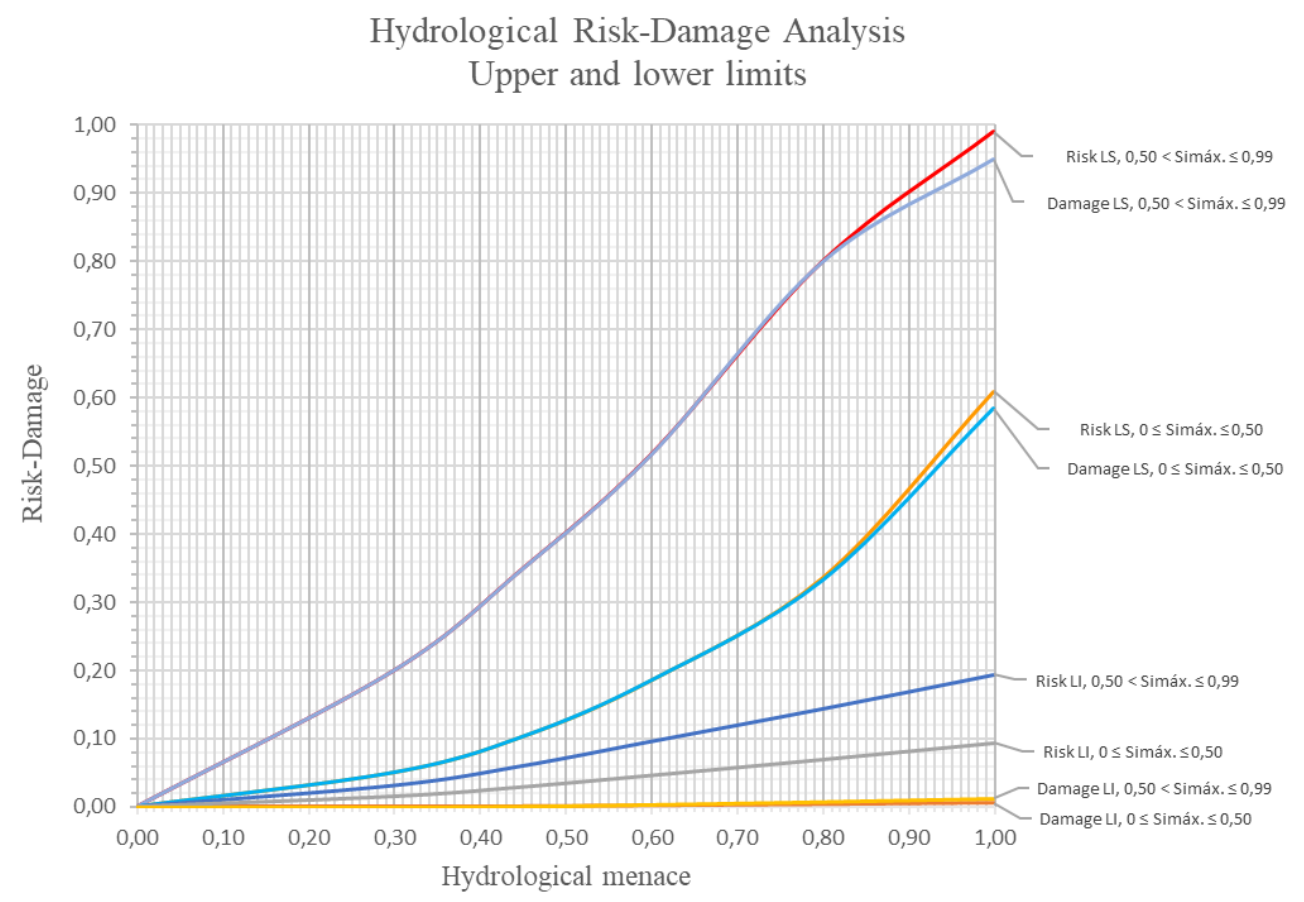

Figure 16. Evolution of risk and potential damage, according to ranges and maximum and minimum limits, also considering the ranges of variation of susceptibilityIsi, $(0 \leqslant$ Isimax. $\leqslant 0.50$ and $0.50<$ Isimax. $\leqslant 0.99$ ), according to hydrological hazard level. Source: Prepared by the authors.

According to the analytical development carried out with respect to the components of risk and specifically the estimated $\lambda$ coefficient, this varies according to the variable range with the hazard and the level of susceptibility and the degree of resilience, also considering factors external to the system which are also variable and which evolve 
according to a mathematical function of the type indicated in Figures 15 and 16, and which takes the form of a lambda coefficient " $\lambda$ ".

In relation to the variability of the coefficient $\lambda$, a variable dependent on factors external to the water infrastructure system, the variability (upper and lower limits) is indicated according to the level of threat, a risk $\mathrm{R}=0.99$ and a susceptibility index $>0.50$. Resilience range, $\alpha(0.15$ and 0.99$)$ and represented in Figure 17:

Coefficient evolution $\lambda$ vs Menace, $\mathrm{A}_{\mathrm{H}}$ $\mathrm{f}(0,99 \geq \mathrm{S}>0,50, \alpha) . \mathrm{S}=0,99$. Threshold values Coeff. $\lambda$.

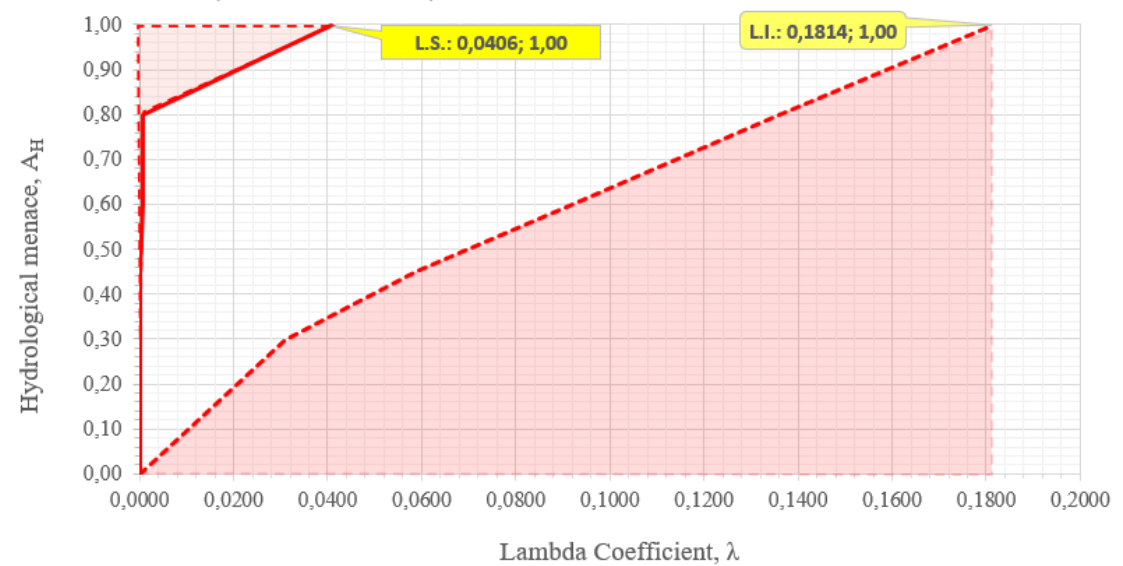

Figure 17. Analysis of the variation of risk and damage limits, as well as susceptibility, according to hydrological hazard level. Source: Prepared by the authors.

In the case of a susceptibility index, $S_{i} \leq 0.50$, the graph of the upper and lower limits shown above, would be according to Figure 18, below.

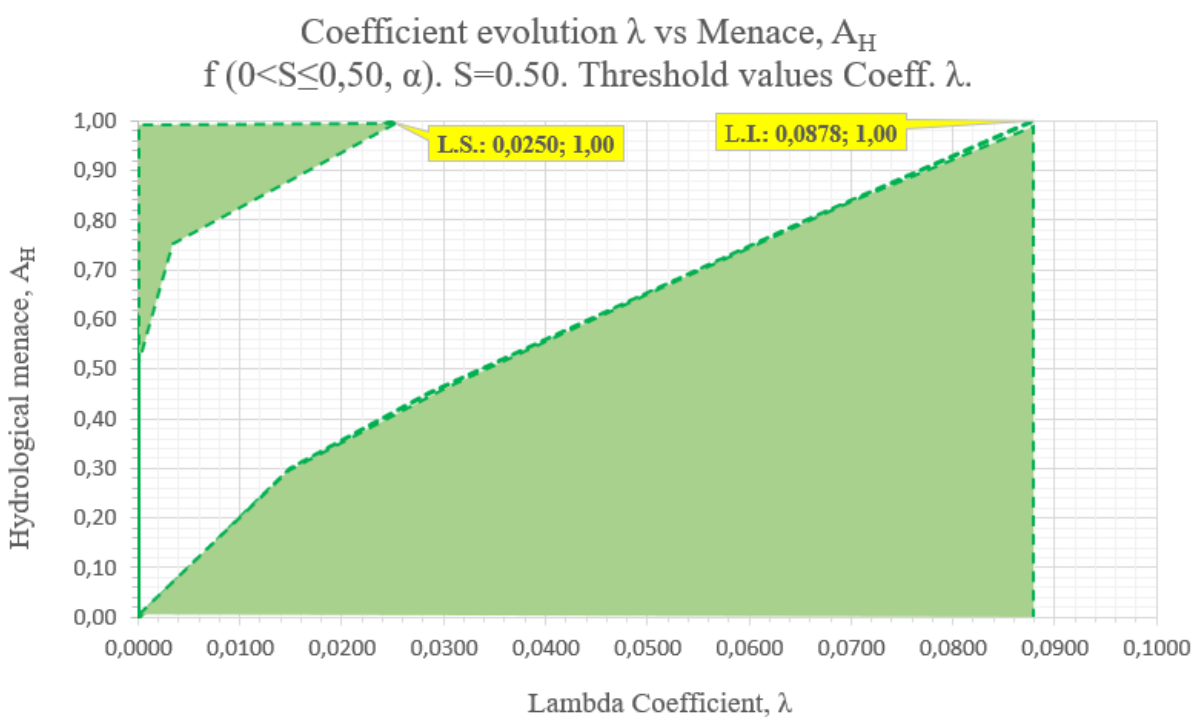

Figure 18. Analysis of the variation of risk and damage limits, as well as susceptibility, $\mathrm{S}_{\mathrm{i}} \leqslant 0.50$, according to hydrological hazard level. Source: Prepared by the authors.

Therefore, this objective has also been fulfilled, obtaining the distribution functions that define the probability of damage in relation to the vulnerability obtained from the hydraulic infrastructure. This approach would allow integrating the representative information of the system in a GIS platform, establishing potential risk scenarios, and developing the resilience of this, the basis for the definition of risk management plans. 
Figures 19 and 20 show the hydrological risk functions, damage and $\lambda$ coefficient according to the maximum and minimum thresholds, in relation to levels I and II of susceptibility of the infrastructure, hydraulic in this case.

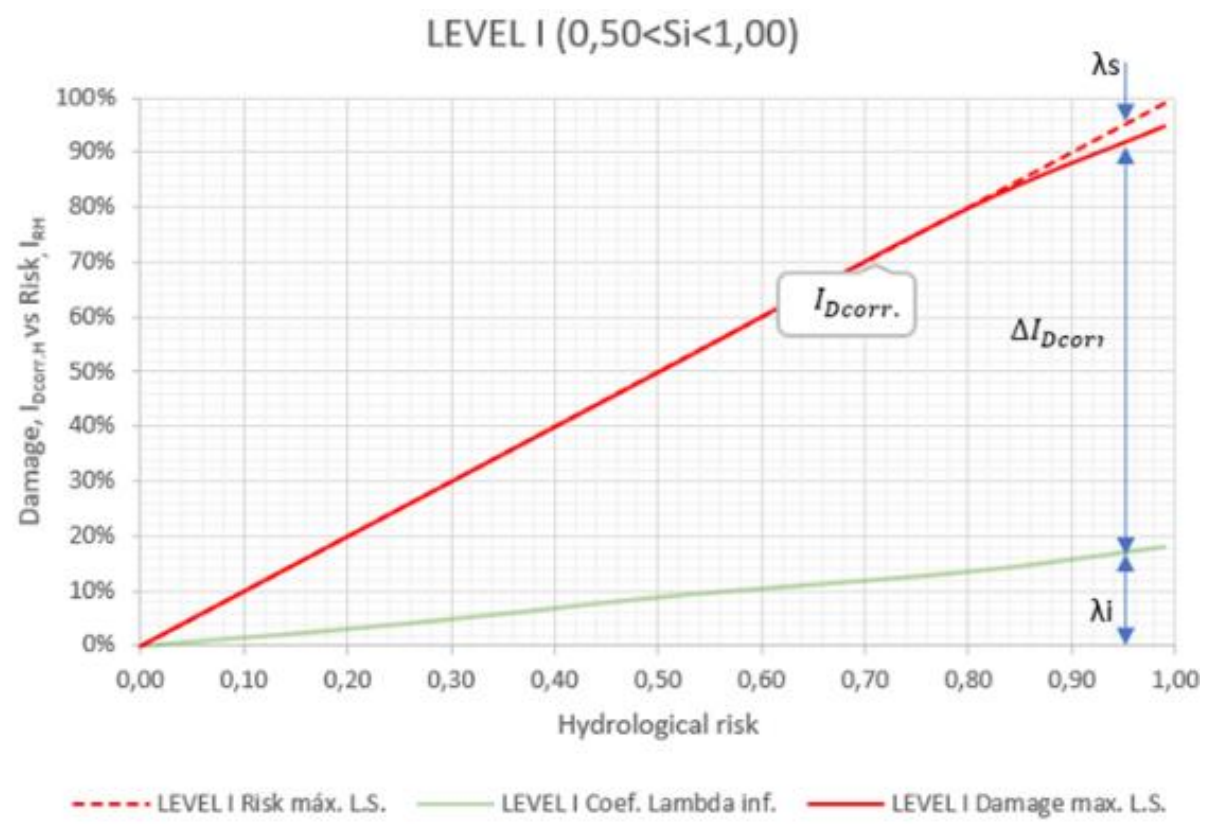

(a)

LEVEL II $(0<\mathrm{Si} \leq 0,50)$

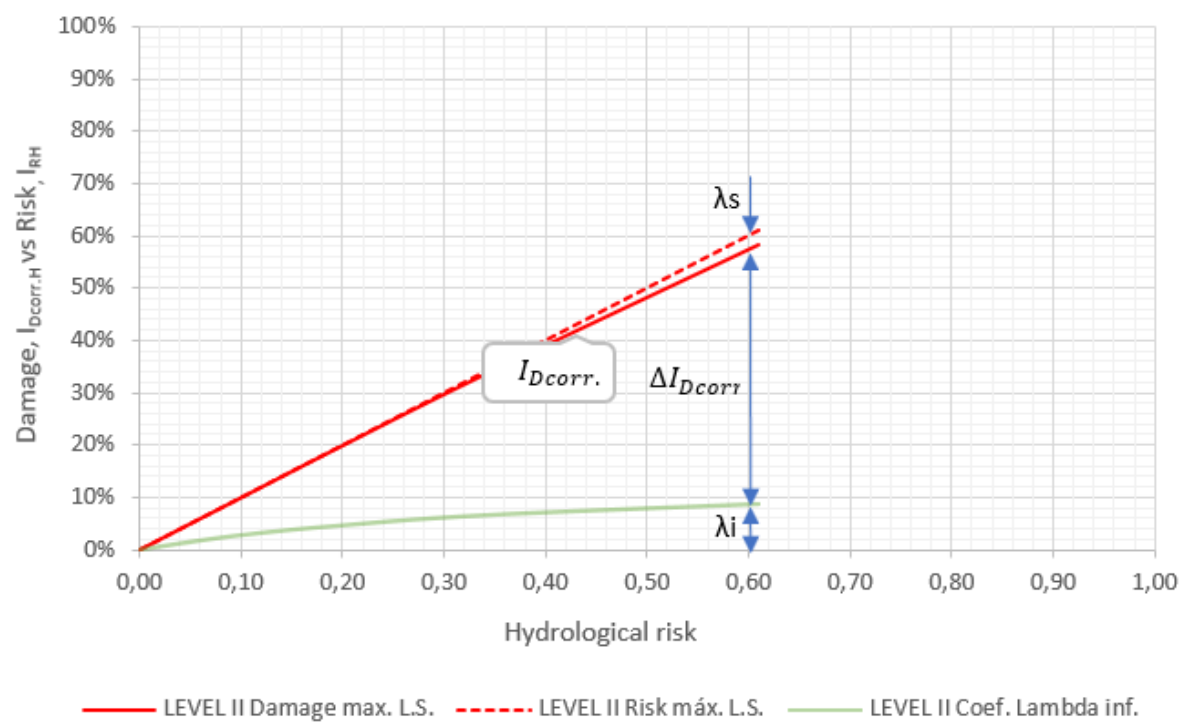

(b)

Figure 19. Maximum hydrologic risk threshold function, the maximum damage index function (maximum threshold) and the lower threshold function of the lambda coefficient $\lambda$, in relation to the damage and risk index: (a) Susceptibility level I; (b) Susceptibility level II. 


\section{LEVEL I $(0,50<\mathrm{Si}<1,00)$}

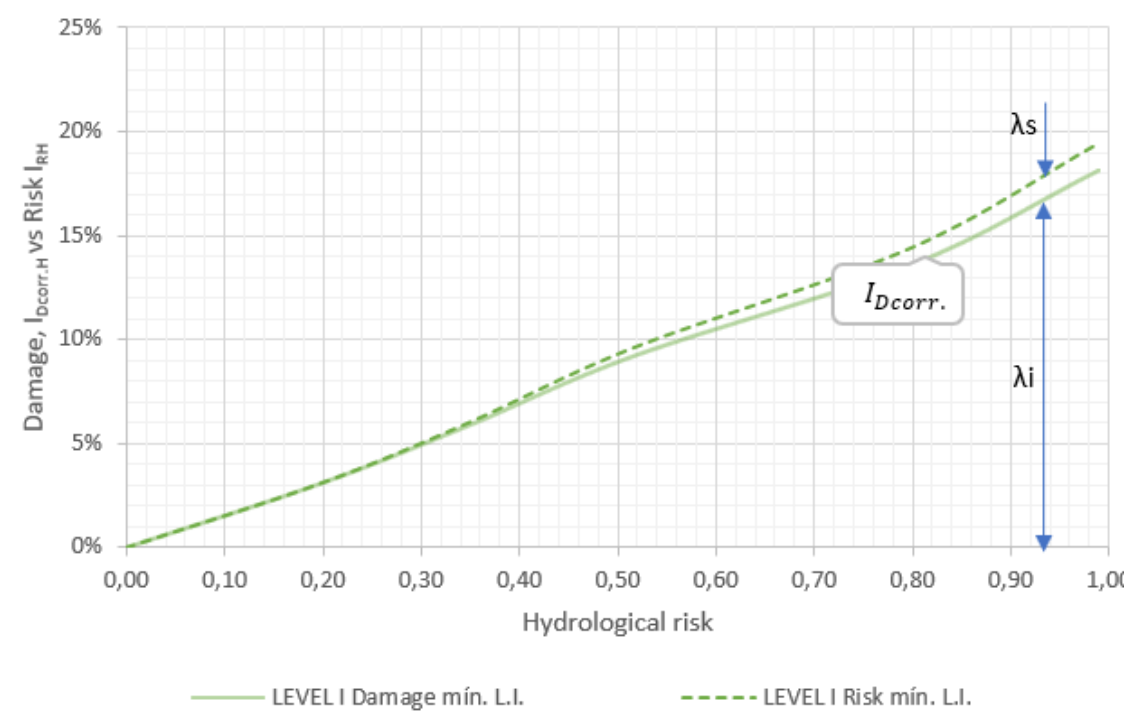

(a)

LEVEL II $(0<\mathrm{Si} \leq 0,50)$

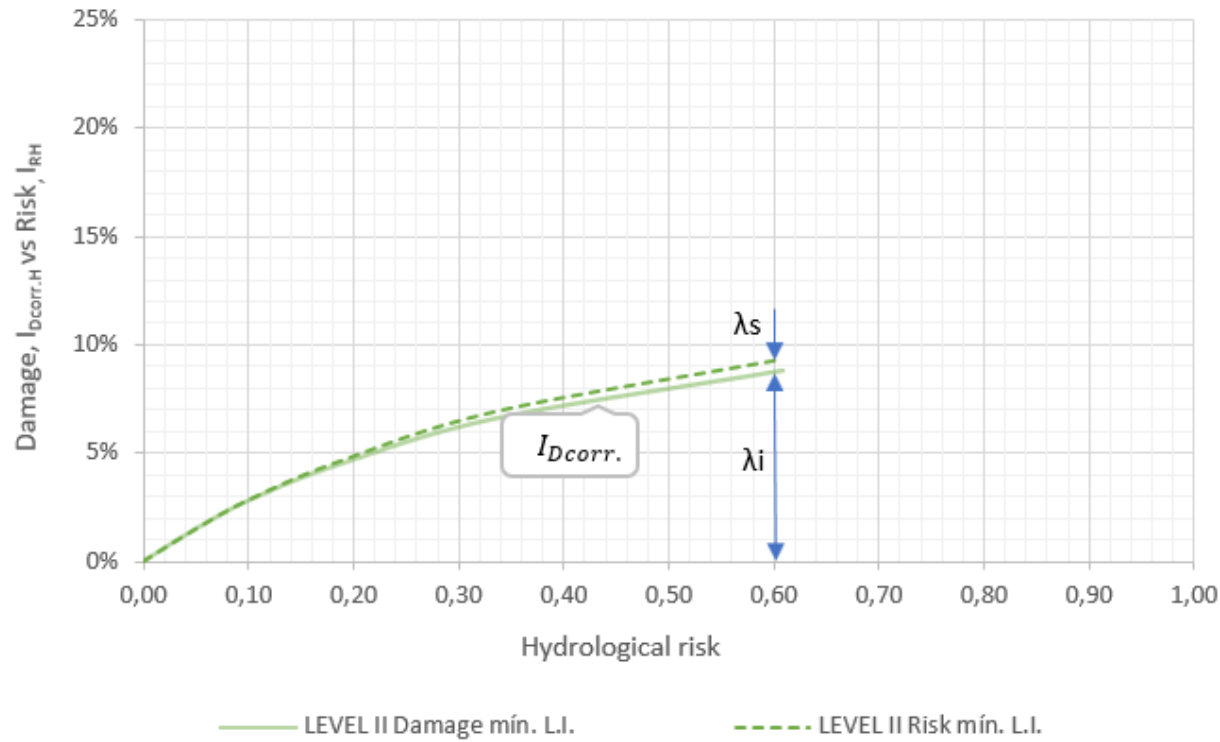

(b)

Figure 20. Function of the minimum threshold of hydrological risk, the function of the minimum damage index (minimum threshold) and the lower threshold of the lambda coefficient $\lambda$, in relation to the damage and risk index: (a) Susceptibility level I; (b) Susceptibility level II.

\section{Conclusions}

It is concluded that the analysis carried out can contribute an improvement to the analysis of the vulnerability of hydraulic infrastructures, having for this purpose an open methodology of a holistic nature based on the construction of indicators that quickly provides information in real time on the possible consequences (damage) that the impact of an episode of flooding would have on a specific infrastructure, both analytically and graphically. Greater knowledge and the linking of all the essential components of risk makes it possible to develop and implement measures and actions aimed at increasing the 
adaptation and response capacity of an infrastructure system, in this case urban hydraulic infrastructures.

The proposed methodology, being holistic and linked, allows its implementation in all critical infrastructures and essential services, enabling easier planning of actions for adaptation to climate change, as well as better and faster decision making. It establishes a guide for the characterization of the infrastructure, previously conceptualizing the variables that intervene and define it, allowing the indicators to be adjusted to the temporal evolution, establishing the following stages:

1. Characterization and analysis of variables, physical and operational parameters.

2. Analysis of historical information on water infrastructure management.

3. Integration of variables and construction of representative indicators.

4. Definition of the management level of the water infrastructure system.

5. Location, characterization, and selection of critical points of the system.

6. Definition of operational efficiency alternatives, continuity of service and application of risk mitigation measures.

7. Analysis of the evolution of management indicators and corrective measures.

8. Development and implementation of a risk management plan for urban water infrastructure (including the different specific operational and emergency plans).

Likewise, the methodology for monitoring the risk management of the hydraulic infrastructure makes it possible to analyze the evolution of the essential parameters, as well as the representative variables, which improves the management and adjustment of these over a time horizon, increasing the resilience of the system.

Author Contributions: Conceptualization, R.E. and J.M.M.; methodology, R.E.; software, F.G.G.; validation, M.C-M.; formal analysis, R.E. and J.M.M.; investigation, R.E.; writing-original draft preparation, R.E. and J.M.M; writing - review and editing, F.N.G. and M.C-M.; visualization, F.N.G. and M.C-M.; supervision, F.N.G. and M.C-M. and J.M.M; All authors have read and agreed to the published version of the manuscript.

Funding: This research received no external funding.

Acknowledgments: Acknowledgment for the support shown for the development of this research to the management company of the drinking water supply and sanitation of the city of Murcia (EMUASA) and the collaborating company Espinagua S.L.U.

Conflicts of Interest: The authors declare no conflict of interest.

\section{References}

1. Arnell, N. W. \& Gosling, S. N. (2016). The impacts of climate change on river flood risk at the global scale. Climatic Change, 134(3), 387-401. https://doi.org/10.1007/s10584-014-1084-5

2. Birkmann, J. (2006). Measuring vulnerability to natural hazards: towards disaster resilient societies. New York, USA: United Nations University Press.

3. Barbat, A. H. \& Cardona, O. D. (2003). Vulnerability and disaster risk indices from engineering perspective and holistic aproach to consider hard and soft variables at urban level. Information and indicators program for disaster risk management. National University of Colombia, Manizales, Colombia, 19.

4. Martínez-Gomariz, E., Forero-Ortiz, E., Guerrero-Hidalga, M., Castán, S. \& Gómez, M. (2020) Flood Depth-Damage Curves for Spanish Urban Areas. Sustainability, 12, 2666. https://doi.org/10.3390/su12072666.

5. Gracia, A., Godé, L. Crego, E., Arrabal, M. A., Guirado, V., García, G., Lobera, C., González, S. \& Martínez, E. (2010, October 2728). Risks and quantification of flood damage. 5th International Congress on Territorial Planning, Sustainable Development and Water Resources Management, Lisbon, Portugal.

6. Hernández-Uribe, R. E., Barrios-Piña, H. \& Ramírez, A.I. (June, 2017). Flood risk analysis: methodology and application to the Atemajac basin. Tecnología y Ciencias del Agua VIII (3):30, 5-25. https://doi.org/10.24850/j-tyca-2017-03-01.

7. Osés-Eraso, N. \& Foudi, S. (2020). Flood risk assessment. Working Paper, 08.

8. Serrano-Lombillo, A., Escuder-Bueno, I., de Membrillera-Ortuño, M. G. \& Altarejos-García, L. (2011). Methodology for the caculation of annualized incremental risks in systems of dams. Risk Analysis, 31(6), 1000-1015. https://doi.org/10.1111/j.15396924.2010.01547.x

9. FEMA (2003). Multi-hazard loss estimation methodology, flood model, HAZUS, technical manual, developed by the Department of Homeland Security, Emergency Preparedness and Response Directorate, FEMA, Mitigation Division, Washington, D.C., under a contract with the National Institute of Building Sciences, Washington, D.C. 
10. FEMA-HAZUS (2004). HAZUS-MH MR2 Technical Manual. Federal Emergency Management Agency.

11. Ministry for Ecological Transition, MITECO (2019). Guide for the Assessment of the Resilience of Urban Areas to Flood Risk: networks, urban systems and other infrastructures. Available online: https://www.miteco.gob.es/es/agua/temas/gestion-de-losriesgos-de-inundacion/guia-evaluacion-resiliencia-nucleos-urbanos-riesgo-inundacion_tcm30-503725.pdf (accessed on 19 July 2021).

12. Yu, J.Z., Whitman, M., Kermanshah, A. H. \& Baroud, H. (2021) A hierarchical Bayesian approach for assessing infrastructure networks serviceability under uncertainty: A case study of water distribution systems, Reliability Engineering \& System Safety, 215, 107735, ISSN 0951-8320, https://doi.org/10.1016/j.ress.2021.107735.

13. Pérez, R. E. (2018). Research on resilient urban water infrastructure management models in relation to hydrological and geological risks. Doctoral dissertation, Universitat d'Alacant.

14. Pérez, R. E., Jaume, A. T. \& Moreno, J. M. (2018). Methodological development for a resilient management of the safety of critical urban water infrastructures. In Congreso Nacional del Agua Orihuela: Innovación y Sostenibilidad (pp. 1525-1538). Universitat d'Alacant.

15. Pinos, J., Timbe, L. \& Orellana, D. (2017). Methods for river flood risk assessment: literature review and methodological proposal for Ecuador. Maskana, 8(2), 147-162. https://doi.org/10.18537/mskn.08.02.11.

16. Gerl, T., Kreibich, H., Franco, G., Marechal, D. \& Schröter, K. (2016) A Review of Flood Loss Models as Basis for Harmonization and Benchmarking. PLoS ONE 11(7): e0159791. https://doi.org/10.1371/journal.pone.0159791.

17. DELNET-UN. (2009). Delnet Programme, Post-Disaster Reconstruction: An opportunity to move towards sustainable development. ILO International Training Centre.

18. Merz, B., Kreibich, H., Schwarze, R. \& Thieken, A. (2010) Review article "Assessment of economic flood damage", Nat. Hazards Earth Syst. Sci. 10, 1697-1724, https://doi.org/10.5194/nhess-10-1697-2010.

19. ISDR-UN. (2000). Disaster Prevention, Education and Youth. The specific case of wildfires.

20. Generalitat Valenciana (2015). PATRICOVA: Territorial Action Plan on Flood Risk Prevention in the Valencian Community.

21. DIRECTIVE 2007/60/EC OF THE EUROPEAN PARLIAMENT AND OF THE COUNCIL of 23 October 2007 on the assessment and management of flood risks.

22. Cardona, O.D. (2004). The need for rethinking the concepts of vulnerability and risk from a holistic perspective: A necessary review and criticism for effective risk management. In: Mapping Vulnerability: Disasters, Development and People. London (UK).

23. Carreño, M.O. (2005). Indicator System for Risk Assessment. Monograph CIMNE IS-52, Technical University of Catalonia. Barcelona (Spain).

24. Russo, B., Gómez, M., Macchione, F., \& de Recerca FLUMEN, G. (2011). Hazard criteria in urban environment. Comparative study between national and international references Topic $\mathrm{C}$ (Water and city).

25. Escuder Bueno, I., Castillo Rodríguez, J. T., Morales Torres, A. \& Altarejos García, L. (2013). Complete and quantitative methodology for flood risk analysis in urban areas. Editorial Universitat Politècnica de València. http://hdl.handle.net/10251/70681.

26. Hammond, M.J., Chen, A.S., Djordjević, S., Butler, D. \& Mark, O. (2015) Urban flood impact assessment: A state-of-the-art review, Urban Water Journal, 12:1, 14-29, DOI: 10.1080/1573062X.2013.857421, https://doi.org/10.1080/1573062X.2013.857421

27. Ten Veldhuis, J.A.E. (2011) How the choice of flood damage metrics influences urban flood risk assessment. Journal of Flood Risk Management, 4 (4), 281-287. [Crossref], [Web of Science ${ }^{\circledR}$ ], [Google Scholar].

28. Ministry for Ecological Transition, MITECO (2017). Guide for Reducing the Vulnerability of Buildings to Floods. Available online: https://www.miteco.gob.es/es/agua/temas/gestion-de-los-riesgos-de inundacion/guia_inundaciones_completa_22jun_tcm30-526164.pdf (accessed on 19 July 2021).

29. Ministry for Ecological Transition, MITECO (2019). Flood Risk Adaptation Guide for agricultural and livestock farms. Available online: https://www.miteco.gob.es/es/agua/temas/gestion-de-los-riesgos-de-inundacion/guia-adaptacion-al-riesgo-inundacion-explotaciones-agricolas-ganaderas_tcm30-503727.pdf (accessed on 19 July 2021).

30. Ministry for Ecological Transition, MITECO (2019). Recommendations for the construction and rehabilitation of buildings in flood zones. Available online: https://www.miteco.gob.es/es/agua/temas/gestion-de-los-riesgos-de-inundacion/guiarecomendaciones-construccion-y-rehabilitacion-edificaciones-zonas-inundables_tcm30-503724.pdf (accessed on 19 July 2021).

31. Ministry for Ecological Transition, MITECO (2019). Sustainable urban drainage systems. Available online: https://www.miteco.gob.es/es/agua/temas/gestion-de-los-riesgos-de-inundacion/guia-adaptacion-riesgo-inundacion-sistemasurbano-drenaje-sostenible_tcm30-503726.pdf (accessed on 19 July 2021).

32. Ministry for Ecological Transition, MITECO (2019). Good practices in actions for the conservation, maintenance and improvement of watercourses. Available online: https://www.miteco.gob.es/es/agua/temas/gestion-de-los-riesgos-de-inundacion/guiabuenas-practicas-en-actuaciones-conservacion-mantenimiento-mejora-cauces_tcm30-503733.pdf (accessed on 19 July 2021).

33. Cardona, O.D. (2006). A System of Indicators for Disaster Risk Management in the Americas in Measuring Vulnerability to Hazards of Natural Origin: Towards Disaster Resilient Societies. Tokyo, Japan: J. Birkmann, United Nations University Press.

34. IDEA (2005). Indicators for Risk Management, IDB Operation ATN/JF-7907-RG. National University of Colombia, Manizales. Available at: http://idea.unalmzl.edu.co. Manizales (Colombia).

35. PAHO, PAHO. (1998). Mitigation of natural disasters in drinking water and sanitary sewerage systems - Guidelines for vulnerability analysis. Pan American Health Organization (PAHO) / Organización Panamericana de la Salud (OPS).

36. Carreño, M.O. (2007b). A disaster risk management performance index. Journal of Natural Hazards, 41(1), 1-20. 